
(C) Kent State University 2013. All rights reserved. Duplication of the material contained herein is strictly prohibited without the express written consent of the Editor of The Journal of SPORT.

ISBN-13: 978-1491096666

ISBN-10: 1491096667

ISSN: 2328-7624 


\section{Contents}

Brand Personalities across the Big Four: Positioning Leagues for Differentiation

Braunstein-Minkove and Ross

Competitive Balance in College Football:

Additional Analysis on the Effects of Changes in Conference Membership

Stoldt, Perline and Vermillion

A Preliminary Investigation of Job Satisfaction of Compliance Officers at NCAA Division II institutions

Parsons, Kaltenbaugh, Brubaker, Winters and Ryan

Incentives on the Starting Grid in Formula One Racing McCarthy and Rotthoff

The Historical Development and Marketing of Fantasy Sports Leagues

Burton, Hall and Paul.............................................. 185

About the Journal of Sport....................................216 

The Journal of SPORT, 2013, 2(2), 111-129

(C) Kent State University

\title{
Brand Personalities across the Big Four: Positioning Leagues for Differentiation
}

\author{
Jessica R. Braunstein-Minkove \\ Towson University \\ Stephen D. Ross \\ University of Minnesota
}

\begin{abstract}
The concept of brand personality (BP) has become a popular topic of study among academicians in the sport management field. The current study moves beyond the construct conceptualization and scale development of $B P$, and begins to investigate existing $B P$ profiles for various professional sports (BPS). Specifically, this research examines the existing BPS dimensions across various Big Four professional leagues. The study utilized the BPS instrument (Braunstein \& Ross, 2009) and MANOVA procedures to determine ratings of $B P$ dimensions and any differences between sports. Results indicated that on the BPS factors that were measured (Success, Sophistication, Sincerity, Rugged, Community-Driven, Classic), sports differed on four of the six factors. For the factors that significantly differed by sport (Success, Sincerity, Rugged, and Classic), the majority of the highest mean scores associated with hockey and baseball. Conceptualizations and scale development of BPS will be discussed along with positioning and segmentation strategies for sport marketers. This paper begins to shift the focus from the concept of BPS to its application. As such, it fills an identified need to determine if there are differences in the "personalities" (i.e., characteristics) of leagues and, ultimately, how these elements can factor into sound and targeted marketing practices.
\end{abstract}


A true test of effective communication is the consumer's clear and consistent understanding of the producer's (intended) message. According to Reis and Trout (1969), it is the marketer's role to alter the product in the consumer's mind rather than the product itself through the branding or "positioning" process. Evolving from the idea that marketing is most effective when the characteristics of the brand "match" those of the endorsers and/or consumers (e.g., Kamins, 1990; Lynch \& Schuler, 1994), Aaker (1997) developed five dimensions of brand personality (BP; i.e., Sincerity, Excitement, Competence, Sophistication, Ruggedness) in order to strategically approach this process. Beyond Aaker's original development, academics have studied BP to determine its use and effectiveness in various circumstances (e.g., de Chernatony, 2001; Keller, 2003). As such, sport marketers have begun to adapt and adopt the study of brand personalities (i.e., brand personality in sport or BPS; Braunstein \& Ross, 2009), or character traits associated with a product (both developed and perceived), in order to effectively understand and, therefore, communicate the sport brand. As a result of the crowded nature of the sport marketplace, ensuring that this message is appropriately received, and understood in the way it is intended, is often vital to the success of a sport entity.

\section{Brand Personality}

Brand personality (BP) has been defined as "the set of human characteristics associated with a brand" (Aaker, 1997, p. 347), and is often used to describe a brand in relation to human characteristics. It is obvious that a great number of different descriptors can be attributed to both brands as well as individuals. Such characteristics include, but are not limited to, sporty, hardworking, intelligent, or even "old school." Aaker (1997) suggests that a brand's uniqueness in terms of brand personality might be used as a means to increase brand awareness and attachment, in much the same way that individuals might attach to other people.

Brand personality can be conceptualized from two different perspectives (Plummer, 1985); brand position and brand identity. Brand position is the perspective of the individual consumer, and describes how these consumers interpret the brand (Gwin \& Gwin, 
2003). This interpretation is how the consumer actually views the brand (Nandan, 2005), and is constructed though a variety of sources such as price, distribution outlets, geographic origins, and marketing campaigns established by the organization. In the sport context, previous research (Gladden, Milne, \& Sutton, 1998; Gladden and Milne, 1999) has suggested many antecedents that will influence the creation of this brand image for consumers (e.g., logo design, coach, team performance).

The brand identity perspective views the brand personality from the organizational perspective, and is the desired brand image of the organization. Organizations spend great deals of money on attempting to create a specific brand personality in the eyes of consumers, and the outcomes of these efforts are often different from the intended message. Given that consumer perceptions are filtered through a myriad of personal experiences, cultures, outcomes and other marketplace factors, marketers can only control about one-half of the "fate" of their brands (Tan Tsu Wee, 2004). Because a substantial amount of the constructed brand personality is out of management control, sport marketers must understand the specific elements that can influence and help to create a positive BP.

\section{Importance of Measuring BP}

It has long been suggested that BP can influence the success of a product in the market (Ogilvy, 1983), and that the loyalty of the customer can strongly influence the perceived brand personality (Karande, Zinkhan, \& Lum, 1997). Loyalty is clearly important for the financial success of sport organizations, and if a consumer has negative view of a sport organization, then the likelihood of consumer loyalty is minimized. Conversely, a sport organization that holds positive images with consumers has a greater potential for attaining significant loyalty among customers (Aaker, 1996).

The measurement and subsequent management of BP is not only important for marketers, but is also an under researched area in sport marketing. Decision-making is a complex phenomenon, and unique BP factors provide a point of differentiation for organizations that might aid in a consumer's decision-making process. The management of BP includes the development and augmentation of a 
set of intangible brand attributes such as user imagery, brand origin, suggested brand values, and brand-consumer relationships (Elliott, 1994; Fournier, 1998) through the manipulation of the marketing mix. However, regardless of the investment in time and resources by the sport organization, the actual customer experience is strongly influential in the constructed BP. That is, sport is intangible, subjective, and unpredictable, with customers being highly involved in helping to create the product experience through simultaneous production and consumption (Lovelock, 1996).

Many studies have sought to conceptualize the construct and develop valid and reliable measurements in the general marketing literature (e.g., Aaker, 1997; de Chernatony, 2001; Keller, 2003) as well as sport (e.g., Gladden \& Funk, 2002; Parent \& Séguin, 2008). Most recently, Braunstein and Ross (2009) began the process of developing the Brand Personality in Sport (BPS) scale that assesses these dimensions in the unique industry that is sport (Success, Sophistication, Sincerity, Rugged, Community-Driven, Classic). While the various measurement techniques can be debated, as with all scales, this research seeks to move beyond the scale development stage and investigate the interrelationship of BPS with other constructs.

\section{Study Purpose}

As the industry has evolved, the likelihood of differentiating the core product among professional sport teams has been reduced. Therefore, teams and leagues are attempting to find specific attributes that can be utilized as points of differentiation. That is, the sport marketplace has become extremely saturated, and the competition among leagues and teams to attract the attention of customers has skyrocketed in the past decade. Sport organizations are clamoring to find and develop strategies to gain the attention (and subsequent patronage) of consumers, financial and in-kind support from sponsors, along with air and web time from media outlets. As such, sport organizations are attempting to find ways to set their product apart from others, and establish the organization as a unique and beneficial investment for consumer and sponsors alike. BPS can serve as one point of differentiation for these organizations. 
Quite often, certain stereotypical attributes are associated with certain sports. For example, hockey and football anecdotally have the reputation of being tough and physical sports, whereas baseball and basketball are more associated with attributes of being technical in nature. Could these sports differentiate themselves based on BPS dimensions? Could the NHL or the NBA utilize certain dimensions of BPS as a marketing strategy? With these questions in mind, the purpose of this research is to take Braunstein \& Ross' (2009) research one step further in order to examine the application of the BPS scale and assess its functionality in determining the brand personality of professional sport leagues. As such, the current study examined differences in BPS factors across the Big Four sport leagues (i.e., NFL, NHL, MLB, NBA), ultimately providing a new technique for sport marketers to evaluate and develop more strategic approaches to their marketing practices.

\section{Method}

Data were collected from 449 students affiliated with two universities. Two different universities in varying geographic locations were selected in order to collect diverse information regarding professional teams and account for regional differences. Students enrolled in a number of sport management, kinesiology, and general business courses were offered the opportunity to volunteer as study participants. The use of students was considered appropriate given that they are significant consumers of sport, and the use of this population is common in brand choice research in sport marketing (e.g., Biswas \& Sherrell, 1993; Ross, 2008).

First, respondents were asked to list one specific sport team to use throughout the survey. A total of 28 surveys were eliminated from final analysis, as the teams listed were not one of the Big Four sports (final dataset $\mathrm{N}=421$ ). These teams were then categorized into the four sports to be utilized for analysis; football $(\mathrm{N}=205)$, baseball $(\mathrm{N}=124)$, basketball $(\mathrm{N}=50)$, and hockey $(\mathrm{N}=42)$.

Based on the review of literature and observations, the measure of BPS was drawn from Braunstein and Ross' (2009) work, including 40 items under six factors: Success with 14 items (e.g., efficient, dependable, superior), Sophistication with 10 items (e.g., 
stylish, glamorous, trendy), Sincerity with 7 items (e.g., honest, genuine, sincere), Rugged with 3 items (e.g., bold, daring, rugged), Community-Driven with 3 items (e.g., authentic, inspirational, service-oriented), and Classic with 3 items (e.g., traditional, classic, old fashioned). Participants rated the degree to which they perceived each of the statements as accurately describing the professional team that they noted at the beginning of the survey. All items were measured on a seven-point scale, where $1=$ 'Totally Disagree' and 7 $=$ 'Totally Agree'.

\section{Data Analysis}

LISREL 8.54 was used to compute the confirmatory factor analysis of the BPS scale. The goodness-of-fit measures used in the study were Steiger's (1998) root-mean-square-error of approximation (RMSEA), the Tucker-Lewis Index (TLI) (Tucker \& Lewis, 1973), and the comparative fit index (CFI) (Bentler, 1990). In terms of reliability, the most important concern is the consistency of items within a measure. The reliability estimates for the scale were measured using the Cronbach's alpha correlation coefficient and the average variance extracted (AVE). Cronbach's alpha coefficient tests the homogeneity of all the items in the instrument subscale. In addition to measures of internal consistency, the variance explained by each of the identified constructs relative to the amount of variance attributed to measurement error (AVE) was examined as a measure of reliability (Fornell \& Larcker, 1981). In addition to evaluating the goodness of fit indices through the confirmatory factor analysis (CFA), and examining the reliability estimates, the construct validity was further examined through tests of discriminant and convergent validity. Convergent validity was assessed by examining each items loading on the construct on which it loaded, and the standard error for which it was associated (Anderson \& Gerbing, 1988). Discriminant validity was assessed through two methods: examination of the correlations between constructs (Anderson \& Gerbing, 1988), and evaluation of the AVE values (Fornell \& Larker, 1981).

Using the general linear model (GLM) procedure in SPSS 16.0, a multivariate analysis of variance (MANOVA) procedure was 
conducted to examine any differences in BPS dimensions across four different sports. Univariate tests (tests of between-subject effects) provided with the MANOVA analysis was examined to determine the specific relationships between sport and BP dimensions. A series of pos-hoc tests were also conducted to examine the differences found between sports.

\section{Results}

The results of the CFA indicated that the data does provide an adequate fit to the model $(\mathrm{RMSEA}=.067, \mathrm{TLI}=0 . .964, \mathrm{CFI}=$ 0.966). The reliabilities for all 6 factors met the minimum suggested levels of .70 (Nunnally \& Bernstein, 1994). While the AVE values for 3 of the 6 factors did fail to achieve the recommended level of .50 (Fornell \& Larcker, 1981), due to the exploratory nature of the study, all factors were kept in the analysis (See Table 1).

Table 1. Factor Reliabilities, AVE, Item Loadings, Standard Errors, and T-values for the BP Dimensions

\begin{tabular}{lccccc}
\multicolumn{1}{c}{ Item } & $\alpha$ & AVE & $\begin{array}{c}\text { Factor } \\
\text { Loading }\end{array}$ & $\begin{array}{c}\text { Standard } \\
\text { Error }\end{array}$ & $t$ \\
\hline Success & .94 & .52 & & & \\
1. successful & & & .784 & .041 & 18.95 \\
2. efficient & & & .759 & .041 & 18.10 \\
3. high-performance & & & .757 & .042 & 18.02 \\
4. dependable & & & .750 & .042 & 17.79 \\
5. superior & & & .742 & .042 & 17.53 \\
6. accomplished & & & .741 & .042 & 17.48 \\
7. respected & & & .722 & .042 & 16.86 \\
8. reliable & & & .720 & .042 & 16.86 \\
9. confident & & & .718 & .043 & 16.81 \\
10. quality & & & .674 & .043 & 16.75 \\
11. consistent & & & .664 & .044 & 15.40 \\
12. capable & & & .645 & .044 & 14.14 \\
13. mature & & & & .044 & 14.54 \\
14. hard-working & .86 & .39 & & & \\
Sophistication & & & .749 & .043 & 17.24 \\
1. stylish & & & & &
\end{tabular}


2. up-to-date

3. appearance

4. glamorous

5. flashy

6. trendy

7. upper class

8. sophisticated

9. attractive

10. corporate

Sincerity

1. honest

2. genuine

3. sincere

4. down-to-earth

5. charming

6 . friendly

7. family-oriented

Rugged

1. bold

2. daring

3. rugged

Community-Driven

1. authentic

2. inspirational

3. service-oriented

Classic

1. traditional

2. classic

3. old fashioned

.667

.657

.651

.641

.612

.608

.601

.591

.397

.85

.44

$\begin{array}{lll}.764 & .043 & 17.54 \\ .681 & .045 & 14.99 \\ .644 & .046 & 13.94 \\ .643 & .046 & 13.91 \\ .643 & .046 & 13.91 \\ .640 & .046 & 13.84 \\ .635 & .046 & 13.71\end{array}$

.70

.45

.829

.693

.423

.048

.049

.052

16.99

14.09

8.13

.76

.51

$\begin{array}{lll}.803 & .043 & 18.55 \\ .753 & .044 & 17.02 \\ .570 & .047 & 11.95\end{array}$

.77

.53

$\begin{array}{lll}.801 & .045 & 17.61 \\ .754 & .046 & 16.34 \\ .625 & .04 & 12.95\end{array}$

Discriminant validity was assessed through two methods:

examination of the correlations between constructs (Anderson \& Gerbing, 1988), and evaluation of the AVE values for each factor (Fornell \& Larker, 1981). No correlation failed the initial test, however, the AVE test of discriminant validity suggested that several of the proposed factors correlate with factors from which they should differ. The convergent validity of the scale was examined by inspecting each items loading on the construct on 
which it loaded, and the standard error for which it was associated (Anderson \& Gerbing, 1988). The results of the data analysis indicate each of the items met this criterion. Research (Browne, MacCallum, Kim, Andersen, \& Glaser, 2002; Hair, Anderson, Tatham, \& Black, 1998) also suggested that when examining the residual matrix, the standardized residuals should not exceed a 2.58 absolute value. Only a small portion of the standardized residuals $(11.9 \%)$ in the current research surpassed this criterion.

A MANOVA procedure was used to assess whether there were significant differences across the four sports with respect to the dimensions of brand personality. In general, all BP dimensions were rated high; that is, above the mid-point of 4.0 (see Table 2). The Wilks Lambda multivariate test of overall differences among groups was statistically significant $(\mathrm{F}=(18,1165)=7.220, \mathrm{p}<.001)$. Univariate between-subjects tests showed that sport type was significantly related to Success $(\mathrm{p}<.05)$, Classic $(\mathrm{p}<.001)$, Rugged $(\mathrm{p}<.001)$, and Sincerity $(\mathrm{p}<.05)$. Conversely, there was no significant relationship between sport type and Sophistication $(p=.145)$ and CommunityDriven $(p=.151)$.

Table 2. A Comparison of BP Dimensions by Sport: Means (Standard Deviations), F-statistics, and p-value.

\begin{tabular}{|c|c|c|c|c|c|c|c|}
\hline \multirow[b]{3}{*}{ BP Dimension } & \multirow[b]{2}{*}{$\begin{array}{c}\text { Total } \\
\text { Sample }\end{array}$} & \multicolumn{4}{|c|}{ Sport } & \multirow{3}{*}{$\begin{array}{c}\mathrm{F} \\
\text { Statistic }\end{array}$} & \multirow{3}{*}{$\begin{array}{c}p \\
\text { value }\end{array}$} \\
\hline & & Football & Baseball & Basketball & Hockey & & \\
\hline & & & & & & & \\
\hline Success & $\begin{array}{c}5.16 \\
(1.05)\end{array}$ & $\begin{array}{c}5.21 \\
(1.00)\end{array}$ & $\begin{array}{c}5.05 \\
(1.06)\end{array}$ & $\begin{array}{c}4.94 \\
(1.29)\end{array}$ & $\begin{array}{c}5.52 \\
(0.82)\end{array}$ & 3.04 & $<.05$ \\
\hline Sophistication & $\begin{array}{c}4.66 \\
(1.04)\end{array}$ & $\begin{array}{c}4.71 \\
(1.05)\end{array}$ & $\begin{array}{c}4.49 \\
(1.07)\end{array}$ & $\begin{array}{c}4.78 \\
(1.11)\end{array}$ & $\begin{array}{c}4.82 \\
(0.80)\end{array}$ & 1.80 & n.s. \\
\hline Classic & $\begin{array}{c}4.68 \\
(1.35)\end{array}$ & $\begin{array}{c}4.66 \\
(1.40)\end{array}$ & $\begin{array}{c}5.12 \\
(1.06)\end{array}$ & $\begin{array}{c}3.86 \\
(1.40)\end{array}$ & $\begin{array}{c}4.42 \\
(1.27)\end{array}$ & 11.83 & $<.001$ \\
\hline Rugged & $\begin{array}{c}4.67 \\
(1.19)\end{array}$ & $\begin{array}{c}4.96 \\
(1.15)\end{array}$ & $\begin{array}{c}4.12 \\
(1.17)\end{array}$ & $\begin{array}{c}4.38 \\
(1.03)\end{array}$ & $\begin{array}{c}5.18 \\
(0.87)\end{array}$ & 18.29 & $<.001$ \\
\hline
\end{tabular}




\begin{tabular}{lccccccc}
\hline & & & & & & & \\
Community- & 5.01 & 5.11 & 5.00 & 4.67 & 5.02 & 1.77 & n.s \\
Driven & $(1.20)$ & $(1.26)$ & $(1.11)$ & $(1.26)$ & $(1.20)$ & & \\
Sincerity & 4.73 & 4.64 & 4.89 & 4.46 & 4.98 & 3.30 & $<.05$ \\
& $(1.07)$ & $(1.19)$ & $(0.95)$ & $(0.95)$ & $(0.77)$ & & \\
\hline
\end{tabular}

Note. ${ }^{\mathrm{a}} 1=$ Not at all Descriptive; $7=$ Extremely Descriptive

Post- hoc tests indicated that those who listed hockey teams were significantly different from those who listed basketball $(\mathrm{p}<.05)$ on the Success dimension. Specifically, respondents who listed hockey teams rated the Success characteristic higher than those who listed basketball teams. Post-hoc tests also revealed that those who listed football teams were significantly different than those who listed baseball $(\mathrm{p}<.01)$ and basketball $(\mathrm{p}<.01)$ teams on the Classic dimension. Those that listed basketball teams were significantly different from those who listed baseball teams $(\mathrm{p}<.001)$, and those that listed baseball team were significantly different from those who listed any other sport team (football, $\mathrm{p}<.01$; basketball, $\mathrm{p}<.001$; hockey, $\mathrm{p}<.05$ ). Additionally, those that listed hockey teams were significantly different from those who listed baseball teams $(p<.05)$ on the Classic dimension. The Rugged factor post-hoc tests indicated significant differences between that those who listed football teams and those who listed baseball $(\mathrm{p}<.001)$ and basketball $(\mathrm{p}<.001)$ teams. Those who listed baseball teams were also different from those who listed hockey teams $(\mathrm{p}<.001)$. The post-hoc comparisons for the Sincerity dimension indicated that those who listed basketball teams were significantly different from those who listed baseball $(p<.05)$ and hockey teams $(p<.05)$, while those who listed baseball teams were significantly different from those who listed basketball teams $(\mathrm{p}<.05)$.

\section{Discussion and Implications}

While the BPS scale does need additional alterations and stronger validity testing, this study provides a basis for that development, as the data did adequately fit the model. Ultimately, these findings provide a platform through which the continued development of the BPS scale can provide a tool through which both theoretical and practical implications may be drawn. Post-hoc tests 
on these factors provided preliminary evidence to support the general claim that sports have distinct characteristics associated with them, seen by sport marketers as well as sport consumers.

For the factors that significantly differed by sport (Success, Classic, Rugged and Sincerity), the majority of the highest mean scores were associated with hockey and baseball. While this may seem logical to the untrained eye, marketers often veer from traditional characteristics when trying to think outside of the box and develop unique tactics to attract consumers. As the competition for the sport consumer dollar increases, the need to find new and innovative promotional strategies is also heightened. These strategies could be utilized to develop new customers through the manipulation of brand personality dimensions, as well as aid in the positioning of the brand as compared to rival leagues. In fact, branding theory suggests differentiation from competitors might be the key to developing new customers and retaining existing customers (Cornwall, Roy, \& Steinard, 2001).

One point of differentiation for these leagues is brand personality, and thus discovering where these differences occur is vitally important. By investigating current personalities that leagues possess, sport marketers can either augment or strengthen specific BPS dimensions to achieve marketing objectives. For example, the current research identified baseball teams as holding a stronger characteristic of the Classic factor than any of the other Big Four sport teams. Marketers for specific MLB teams, or even the League itself, could utilize promotional strategies that emphasize elements of being old-fashioned and traditional. In fact, the MLB All-Star game is often referred to as the Summer Classic, thus perpetuating the Classic brand personality attributes. Additionally, the findings that linked hockey with the characteristic of Rugged could influence the NHL to continue, and increase, pursuits such as the Winter Classic, pitting two teams against one another in open-air competition. In addition to Rugged, hockey was also linked to the characteristics of Success and Sincerity. Recently, the NHL tried to capitalize on the factor of (anti)Success, immediately delivering an e-mail to fans whose teams were eliminated from the playoffs, promoting the NHL shop's supply of licensed golf paraphernalia 
(Rogers, 2012). While the players themselves might have hit the links shortly after the game ended, this would not be a recommend strategy to reach out, and seemingly mock, individuals who are highly identified with your league and its teams. On that same note, Sincerity regarding the league's interest in the fan's level of identification with the team, and sport, can be questioned. This type of marketing tactic forces a consumer to question the league's purpose as a whole. Do they seem them as an invested fan? Or is this individual simply a dollar sign with no emotional connection to the team that they identify with? Perhaps a connection to the concept of Sincerity would have helped the NHL as they progressed through their lockout on the way to a shortened season? While these are only a few examples of the way in which leagues are already (and potentially inadvertently) using these particular characteristics, continued research in this area will provide a stronger sense of the characteristics that the ever-coveted consumer associates with particular sports and sporting entities, as well as whether or not the adaptation of the two non-discriminant factors (i.e., Sophistication, and Community-Driven) (Braunstein \& Ross, 2009) will provide a greater sense of the characteristics associated with sport.

We believe that these findings are vital to the further development of both the theoretical framework and application of the BPS scale. As such, they provide a sound preliminary exploration of the operationalization of brand personality in sport. In addition to expanding upon current theories and applications in this area, this work subscribes to the belief that a scale for both practitioners and academicians can be used to develop a more effective marketing mix for individual sport entities. As the current economic climate continues to impact sport, and marketing budgets are slashed, the further development of tools that provide the opportunity for marketers to take a strategic approach will prove beneficial to academicians as well as practitioners.

\section{Limitations and Future Research}

The first and perhaps most important limitation associated with the current research is the use of one specific brand personality scale. Much debate has occurred over the appropriate method to 
assess BP along with the validity and reliability of existing scales. For exploratory work, these findings were positive; however, as the data only adequately fit the model, and there were concerns with both the AVE values and the discriminant validity of certain factors, there is certainly room for improvement. For further development, it is suggested that additional BP scales, and those similar to the BPS, are reviewed to address both concerns with the model and various unique aspects of the sports industry.

This research also utilized only one previously developed $\mathrm{BP} / \mathrm{BPS}$ scale, and is limited in the results based on this narrowly defined conceptualization of sport brand personality. As this study only relied on this one measure of BPS, we believe that future work could benefit from other measures as well as various approaches to investigating this topic (i.e., exploration beyond traditional "American" sports). Future research should also seek to validate these findings by comparing BP using other previously developed scales, as well as alterations of the BPS.

The sample used as our participant pool (i.e., students) can be seen as a limitation as well. While it has been noted that this is an appropriate group for the purpose of this study, as this age range is made of up significant consumers of sport (e.g., Biswas \& Sherrell, 1993; Ross, 2008), it does limit the applicability of our findings. As the characteristics of sport consumers are so diverse, this should be taken into account in the future. Additionally, the location of these samples, while varying in geographic locations, could have factored in to the sports selected as well as these individual's connections and/or beliefs regarding their personalities.

Due to the methodology of this particular study, the focus was on the Big Four professional leagues (i.e., baseball, basketball, football, and hockey), and future research should also seek to examine the BP from sports other than the traditional Big Four. This research is limited to only these sports, and additional studies could identify potential differences across other sports. While this allowed us to begin examining the general characteristics of sport entities, it is quite limiting. As many sport entities have their own unique personalities that have been carefully crafted and promoted through their own branding, or positioning, process (Reis \& Trout, 1969), it 
is difficult to generalize the characteristics of a league onto all of their teams, as cities and regions have their own unique characteristics or "personalities" that have been reflected through their own adaptation of this process. For example, while the New York Yankees align with the Classic dimension very well (e.g., uniform, history, logo), there are other MLB clubs (e.g., Houston Astros, Tampa Bay Rays) who may not reflect the dimension in the same way due to the evolution of their image. As such, it is vitally important to understand these differences, potentially using this work as a foundation for further exploration among professional leagues, collegiate conferences, and individual teams.

Auto racing (specifically, NASCAR) has grown to epic popularity in the past several years and might offer consumers a different type of outlet for sport consumption. This sport offers a great opportunity to expand BP research outside of the popular American sports. In a related manner, sports that have greater followings on a global level would offer a great opportunity to examine cross-cultural and international perspectives on BP. The sports of soccer, rugby, and cricket are three logical settings to conduct similar research to the current study. Fast growing niche sports also lend themselves well to the expansion of this research topic. It is therefore suggested that this line of work expands beyond "traditional" sports and assess its application with both nontraditional (e.g., action sports, mixed martial arts) and individual sport (e.g., golf, tennis, boxing, swimming) athletes, events, and tours. While this study provides us with a solid platform from both theoretical and practical perspectives, there is much work to be done in order to have a greater understanding of the role that brand personality in sport impacts leagues, teams, and individuals.

\section{Conclusion}

This purpose of this study was to assess the validity and begin the shift of the BPS scale from theory to practice. While additional review and testing will be necessary, we believe that this provides a strong foundation to fulfill an identified need to determine if there are differences in the "personalities" (i.e., characteristics) of leagues. In addition to the academic component of this work, it 
provides "new" elements that sport industry professionals can focus on in developing sound and targeted marketing practices. 


\section{References}

Aaker, D. (1996). Building strong brands. Boston: Free Press.

Aaker, J. L. (1997). Dimensions of brand personality. Journal of Marketing Research, 34, 347-357.

Anderson, J., \& Gerbing, D. (1988). Structural equation modelling in practice: A review and recommended two-step approach. Psychological Bulletin, 10, 411-423.

Bentler, P. (1990). Comparative fit indices in structural models. Psychological Bulletin, 107, 238-246.

Biswas, A., \& Sherrell, D. (1993). The influence of product knowledge and brand name on internal price standards and confidence. Psychology and Marketing, 46(1), 31-46.

Braunstein, J. R., \& Ross, S. D. (2009). Brand personality in sport: Dimension analysis and general scale development. Sport Marketing Quarterly, 19, 8-16.

Browne, M., MacCallum, R., Kim, C., Andersen, B., \& Glaser, R. (2002). When fit indices and residuals are incompatible. Psychological Methods, 7, 403-421.

Cornwall, T., Roy, D., \& Steinard, E. (2001). Exploring managers perceptions of the impact of sponsorship on brand equity. Journal of Advertising, 30(2), 41-51.

de Chernatony, L. (2001) A model for strategically building brands. Journal of Brand Management, 9(1), 32-44.

Elliott, R. (1994). Exploring the symbolic meaning of brands. British Journal of Management, 5, S13-S19. 
Fornell, C., \& Larcker, D. (1981) Evaluating structural equation models with unobservable variables and measurement error. Journal of Marketing Research, 18(1), 39-50.

Fournier, S., \& Mick, D. G. (1999). Rediscovering satisfaction. Journal of Marketing, 63(4), 5-28.

Gladden, J. M., \& Funk, D. C. (2002). Developing an understanding of brand associations in team sport: Empirical evidence from consumers of professional sport. Journal of Sport Management, 16(1), 54-81.

Gladden, J. M., \& Milne, G. R. (1999). Examining the importance of brand equity in professional sport. Sport Marketing Quarterly, 8(1), 21-29.

Gladden, J. M., Milne, G. R. \& Sutton, W. A. (1998). A conceptual framework for assessing brand equity in Division I college athletics. Journal of Sport Management, 12, 1-19.

Gwin, C.F., Gwin, C.R. (2003). Product attributes model: a tool for evaluating brand positioning. Journal of Marketing Theory and Practice, 11(2), 30-42.

Hair, J., Anderson, R., Tatham, R., \& Black, W. (1998). Multivariate data analysis: With readings $\left(5^{\text {th }}\right.$ ed.). New Jersey: PrenticeHall.

Kamins, M. A. (1990). An investigation into the match-uphypothesis in celebrity advertising: When beauty be only skin deep. Journal of Advertising, 19(1), 4-13.

Karande, K., Zinkhan, G., \& Lum, A. (1997). Brand personality and self-concept: A replication and extension. American Marketing Association Educators Proceedings 8 (Summer), 165-171. 
Keller, K. L. (2003). Strategic brand management: Building, measuring and managing brand equity, 2nd Ed. Englewood Cliffs, NJ: Prentice-Hall.

Lovelock, C. H. (1996). Services marketing. New York: Prentice Hall.

Lynch, J., \& Schuler, D. (1994). The matchup effect of spokesperson and product congruency: A schema theory interpretation. Psychology and Marketing, 11, 417-445.

MacDonald, R. \& Ho, M. (2002) Principles and practices in reporting structural equation analyses. Psychological Methods, 7(1), 64-82.

Nunnally, J., \& Bernstein, I. (1994) Psychometric theory $\left(3^{\text {rd }}\right.$ ed.) New York: McGraw Hill.

Ogilvy, D. (1983). Ogilvy on advertising. New York: Random House.

Parent, M., \& Séguin, B. (2008). Toward a model of brand creation for international large-scale sporting events. Journal of Sport Management, 22, 526-549.

Ries, A., \& Trout, J. (1969). Positioning: The battle for your mind. New York: McGraw-Hill.

Rogers, D. (May 7, 2012). Shop NHL's marketing strategy angers fans. Bloguin. Retrieved from: http://bloguin.com/puckdrunklove/2012-articles/may-shopnhls-marketing-strategy-angers-fans.html

Ross, S. D. (2008). Assessing the use of the brand personality scale in team sport. International Journal of Sport Management and Marketing, 3(1/2), 23 - 38. 
Tan Tsu Wee, T. (2004). Extending human personality to brands: the stability factor. Brand Management, 11(4), 317-330.

Tucker, L., \& Lewis, C. (1973). A reliability coefficient for maximum likelihood factor analysis. Psychometrika, 38, 110. 
The Journal of SPORT, 2013, 2(2), 130-153

(C) Kent State University

\title{
Competitive Balance in College Football: Additional Analysis on the Effects of Changes in Conference Membership
}

\author{
G. Clayton Stoldt \\ Wichita State University \\ Martin M. Perline \\ Wichita State University \\ Mark C. Vermillion \\ Wichita State University
}

\begin{abstract}
Numerous studies (Perline \& Stoldt, 2007; Perline, Stoldt \& Vermillion, 2012: Rhoads, 2004) have indicated that changes in college athletic conference membership at the NCAA Division I FBS level result in greater levels of competitive balance in football. The purpose of this study is to determine if member churning in the Atlantic Coast Conference (ACC) and the Big East between the years of 1999 and 2011 led to a greater degree of competitive analysis. Three methods of assessing competitive balance were employed. Two - the standard deviation of winning percentages and the Hirfindahl-Hirschman Index - are commonly used in competitive balance studies. The authors included range of winning percentages as an additional method. Results indicate that competitive balance in football improved in both conferences after changes in membership. This aligns the findings of this study with previous research and supports the contention that football is the primary consideration when conferences make changes in their membership (Fort \& Quirk, 1999).
\end{abstract}


Over the next four years, 32 institutions will change conference affiliation for football at the NCAA Division I Football Bowl Subdivision (NCAA D-1 FBS) level ("NCAA Division I...," 2012). The last 10 years saw 30 NCAA D-I FBS schools change conference affiliation for football (NBC Sports, n.d.). The reasons for these changes in conference membership, often referred to as member churning, are myriad, ranging from political squabbles (see, for example, the case of Texas A\&M as described in Halliburton, 2011; Wieberg \& Berkowitz, 2011) to opportunities to achieve automatic qualifier status for the now soon-to-be extinct Bowl Championship Series (see, for example, the case of Boise State as described in NewsCore, 2012). Economic considerations are often a major factor in realignment decisions (Depken II, n.d.; Mitchell, 2011; Thamel, 2011; Wieberg \& Berkowitz, 2011). Further, football has been identified as the key sport in realignment decisions (Fort \& Quick, 1999; Thamel, 2011; Wieberg \& Berkowitz, 2011). Certainly, competitive balance is a relevant consideration in discussions about the effects of member churning. It is related to revenue maximization because of its relationship to consumer demand (Depken \& Wilson, n.d; Dittmore \& Crow, 2010; Humphreys, 2002; Rein, Kotler \& Shields 2006; Rhoads, 2004). The uncertainty of outcome hypothesis states that fan interest (e.g., ticket sales, television viewership) is higher for games between more equally matched opponents than for games featuring mismatches. There are also ethical dimensions to competitive balance in college sports, as providing a level playing field for member institutions is one of the goals of athletic conferences (Rhoads, 2004; Staurowsky \& Abney, 2011).

Several studies have been conducted over the last decade examining the effects of member churning on competitive balance in conferences at the NCAA D-I FBS level. Conferences studied have included the Big XII (Perline \& Stoldt, 2007), Conference USA (Perline, Stoldt \& Vermillion, 2012), Mountain West (Rhoads, 2004) and Western Athletic Conference (Rhoads, 2004). In each case, analysis of competitive balance in the sport of football has indicated an improvement in competitive balance after the most recent round 
of churning (Perline \& Stoldt, 2007; Perline et al, 2012; Rhoads, 2004).

Given past studies, it seems appropriate to further investigate whether increased churning leads to the same results. The purpose of this study, then, is to analyze how member churning affects competitive balance in college football for conferences at the NCAA D-I FBS level. To investigate this, we compare competitive balance in two conferences, the Atlantic Coast Conference (ACC) and the Big East, before and after membership changes that occurred following the 2003 and 2004 seasons. After those seasons, the ACC grew from 9 to 12 teams, and the Big East welcomed six new members after the departure of four others. Such analysis is important as scholars and practitioners continue to ascertain the impact of member churning and related considerations in the sport that drives the process of realignment.

\section{Literature Review}

The review of salient scholarship with regards to competitive balance in this research is organized into three sections. The first section provides relevant background information on the nature of athletic conferences in college sports, while the second section reviews the research that has examined the effects of member churning on competitive balance within athletic conferences. Finally, the third section offers specific background information on the ACC and Big East, including recent changes in membership within those conferences.

\section{College Conferences}

Intercollegiate athletic conferences are a part of the governance structure administering collegiate athletics (Barr, 1998). As constructed, the conferences serve many functions. These functions include providing competitive opportunities for member institutions (Staurowsky \& Abney, 2011), while delivering of a range of services to member schools (Barr, 1998). Athletic conferences, additionally, assist in generating and subsequently organizing how revenue is distributed to member schools (Depken II, n.d; Grant, Leadley \& 
Zygmont, 2008). One of the goals of athletic conferences is to "sustain a level playing field for member institutions" (Staurowsky \& Abney, 2011, p. 149) and in so doing, facilitate some level of competitive balance (Rhoads, 2004).

As previously noted, competitive balance is associated with maximizing revenue (Depken \& Wilson, n.d.; Dittmore \& Crow, 2010; Humphreys, 2002; Rein, Kotler \& Shields 2006; Rhoads, 2004). There are many ways conferences can generate revenue for distribution to member schools. Two of these major strategies include staging championship events and distributing conferencespecific sport content through rights-paying media partners or conference media properties (e.g., television network). While consumer demand for both in-person and media consumption of athletic competitions or events is associated with the idea that the event's outcome is not predetermined (Depken \& Wilson, 2005; Dittmore \& Crow, 2010; Humphreys, 2002; Rein, Kotler \& Shields 2006; Rhoads, 2004), higher degrees of competitive balance for conferences may be interrelated to member schools' increased revenues. And to the extent that at least some conference churning at the NCAA I FBS level involved institutions moving from conferences that did not have automatic qualifier (AQ) status in the BCS to those that did hold such status (Perline, Stoldt, \& Vermillion, 2013), realignment has had additional economic ramifications. Caro and Benton (2012) analyzed data from FBS conferences and teams and found that schools in AQ conferences received significantly more football revenue than their non-AQ counterparts.

\section{Competitive Balance}

The scholarship associated with competitive balance specific to intercollegiate athletics has identified a variety of factors and methods for examining the complex nature of intercollegiate athletics. Conference churning can be conceptualized as a form of conference realignment, which is hypothesized to impact competitive balance (Perline \& Stoldt, 2007; Perline et al, 2012; Rhoads, 2004). Indeed, Perline and Stoldt (2007) noted the effect conference churning has upon competitive balance with specific regards to the Big XII. Specifically, there was more competitive 
balance in the first decade of the Big XII as compared to the last decade of the Big 8. Rhoads (2004) examined the churning effect in two conferences and his conclusions also indicated an increased competitive balance in football.

With regards to NCAA FBS (Football Bowl Subdivision) athletics, there are a number of studies highlighting the highly variegated nature, impact, and measurement of competitive balance. Several factors appear to impact competitive balance within intercollegiate athletics, including the NCAA's enforcement of bylaws in 1953, the 1984 Supreme Court ruling that gave individual schools the right to negotiate their own broadcast agreements, and the NCAA's scholarship limitations. Each of these factors are addressed in the following paragraphs.

The NCAA's enforcement of governance and compliance to organizational bylaws, which began in the early 1950s, decreased the competitive balance in college athletics (Eckard, 1998). After studying a number of conferences prior to - and after-1953 when the NCAA began enforcing official rules violations for member schools, Eckard determined the NCAA reduced competitive balance, which was correlated with fewer changes in national and conference rankings. Bennet and Fizel (1995) identified how three decades later-in 1984 - the improvement in competitive balance in college athletics could be associated with the Supreme Court ruling with regards to television distribution rights. Finally, Sutter and Winkler (2003) examined the role scholarship limitations had upon competitive balance. They noted the negative effect these limitations had upon balanced competition.

There are a variety of ways to examine competitive balance, especially within intercollegiate athletics. For example Depken and Wilson (2004) examined first four years of the BCS (Bowl Championship Series for FBS college football) and noted the impact it had on all college football programs. Specifically, they found the BCS did not affect competitiveness in college football when they used the HHI (Hirfindahl-Hirschman Index), which measures the number of teams that are able to become champions within a given period of time (Perline \& Stoldt, 2007). A negative impact on competitive balance, however, was identified when using the SCP 
(Structure-Conduct-Performance) measure, which examines how performance within the industry is associated with market influences. Also using the HHI method, Depken and Wilson (2006) studied the effects of NCAA enforcement on competitive balance in major conferences. The results indicated support for the NCAA's claim that enforcement of its membership enhances competitive balance.

Dittmore and Crow (2010) examined BCS conferences during three five-year periods. The first period was 1993-1997, which was before the BCS was implemented. The second period was 19982002, which was the first five years of the BCS, and the last period was 2003-2007, which was the $2^{\text {nd }} 5$ years of the BCS system. They discovered that the within-season competitive balance, which was measured as the actual standard deviation/ideal standard deviation, improved with the BCS system. According to Dittmore and Crow's (2010) research, the ACC (Atlantic Coast Conference) demonstrated the most improvement in within-season competitive balance, with the addition of three new teams serving as a key factor. Conference realignment in the Big East also contributed to improved competitive balance in the last five-year period (2003-2007). The betweenseason competitive balance, however, improved in only three conferences--the ACC, Big 8/12, and Southeastern Conference--with the other conferences top rated teams remaining relatively unchanged. The present analysis brings these results up-to-date, and thus measures whether these conclusions remain valid.

\section{The ACC and Big East Conference}

As of 2012-13, 11 conferences compete at the NCAA FBS level (ESPN, n.d.), including the ACC and Big East. Both conferences hold AQ status in the Bowl Championship Series (BCS), meaning their champions automatically receive a bid to a BCS game. Although a new college football playoff system has been announced that will no longer include AQs, it will not take effect until 2014 (Dinich, 2012). As a result of the current system and their AQ status, the ACC and Big East enjoy considerable prestige.

The ACC. The ACC was founded in 1953 with seven charter institutions - Clemson College, Duke University, the University of 
Maryland, the University of North Carolina, North Carolina State University, the University of South Carolina, and Wake Forest College (ACC, 2011). The University of Virginia became the eighth member of the conference later that same year, and the ACC enjoyed membership stability until 1971 when South Carolina left the conference (ACC, 2011). In 1978, Georgia Institute of Technology (i.e., Georgia Tech) joined to bring conference membership back to eight. Florida State University joined in 1991 (ACC, 2011). In 2004, Virginia Polytechnic Institute and State University (i.e., Virginia Tech) and the University of Miami brought conference membership to 11 (ACC, 2011). Boston College became the league's $12^{\text {th }}$ member in 2005 (ACC, 2011).

In 2011, the ACC announced that the University of Pittsburgh and Syracuse University would be joining the league effective in 2014 (Smith, 2012). Syracuse subsequently negotiated an early exit from the Big East, which will allow it to join the ACC in 2013 (Smith, 2013). The ACC lost a member in 2012 when Maryland announced it would shift to the Big 10 starting in 2014. However, the conference gained two additional members when the University of Louisville announced it would depart the Big East for the ACC in 2014 (Himmelsbach, 2012) and Notre Dame University announced it would join in all sports except football and hockey in 2015 (Dodd, 2012).

The Big East. The Big East was established in 1979 with seven charter institutions-Boston College, the University of Connecticut (i.e., UConn), Georgetown University, Providence College, Seton Hall University, St. John's University, and Syracuse University (Big East Conference, n.d.a). However, the conference did not stage championship competition in football until 1991 ("Membership Timeline...," n.d.). At that time, Boston College, the University of Pittsburgh (which joined the conference in 1982), and Syracuse were joined by a new member, the University of Miami, and four new associate members competing in football only ("Membership Timeline...," n.d.). The associate members were Rutgers University, Temple University, Virginia Tech, and West Virginia University. Notre Dame joined in 1995, but maintained its independent status in football ("Membership Timeline...," n.d.). 
The Big East experienced considerable churning in the mid2000s. Miami and Virginia Tech departed for the ACC and Temple left for the Atlantic 10 after the 2003 season ("Membership Timeline...," n.d.). Boston College left the Big East for the ACC after the 2004 season. The conference added six new members in 2005, three of whom competed in football ("Membership Timeline...," n.d.). The three football-playing institutions were the University of Cincinnati, the University of Louisville, and the University of South Florida.

The Big East's roster of conference members has changed frequently in recent year, and it will continue do so in the near future. West Virginia departed for the Big 12 in 2012. Texas Christian University jumped to the Big 12 too, marking a change after announcing in 2010 that it would become a member of the Big East in 2012 (ESPN, 2012). Boise State University and San Diego State University, both of which had announced decisions to leave the Mountain West Conference and join the Big East in 2013, opted to reverse course and remain in the Mountain West (Fowler, 2013a; Wolken 2012).

Other changes in membership are also scheduled (Big East, n.d.b). Pittsburgh and Syracuse depart for the ACC in 2013. Rutgers has announced its intention to leave for the Big 10 in 2014 (McMurphy \& O’Neil, 2012) and Louisville (Himmelsbach, 2012) and Notre Dame (Dodd, 2012) have similarly announced moves to the ACC.

The Big East will add the University of Central Florida, the University of Houston, the University of Memphis, Southern Methodist University, and Temple University in 2013. In addition, Tulane University will join the Big East in 2014 as a conference member in all sports. Two other institutions are scheduled to join as football only members - East Carolina University in 2014 and the U.S. Naval Academy in 2015. Despite these gains, the conference's future viability was further muddled by a Dec. 15, 2012 announcement from seven schools, none of which competed within the conference in football, that they would leave the Big East in 2015 (Fowler, 2013b). 


\section{Methods}

As stated, our purpose is to compare competitive balance in two conferences - the ACC and the Big East - before and after membership changes that occurred after the 2003 and 2004 seasons. Specifically, we compare the time periods 1999-2003 and 20052011. Each period represents a multiple-year period when membership was stable in the two conferences. We skip 2004 because it was a year of transition for both conferences. The ACC added Miami and Virginia Tech in 2004, but it did not add Boston College until 2005. Each of the three aforementioned institutions left the Big East, and that conference did not add its six new members until 2005. The 2011 season marked the end of the most recent span of conference stability since West Virginia departed for the Big 12 in 2012.

Table 1 lists the various institutions that were members of the ACC during the time periods being examined. Table 2 serves in like fashion for the football membership in the Big East.

Table 1

Atlantic Coast Conference Membership 1999-2011

\begin{tabular}{cc}
\hline School & Year Joined \\
\hline Boston College & 2005 \\
Clemson & 1953 \\
Duke & 1953 \\
Florida State & 1991 \\
Georgia Tech & 1953 \\
Maryland & 1953 \\
Miami & 2004 \\
North Carolina & 1953 \\
North Carolina State & 1953 \\
Virginia & 1953 \\
Virginia Tech & 2004 \\
Wake Forest & 1953 \\
\hline
\end{tabular}

Source: ACC (2013). 
Table 2

Big East Conference Football Membership 1999-2011

\begin{tabular}{cc}
\hline School & Year Joined \\
\hline Boston College & 1991 \\
Connecticut & 2004 \\
Cincinnati & 2005 \\
Louisville & 2005 \\
Miami & 1991 \\
Pitt & 1991 \\
Rutgers & 1991 \\
South Florida & 2005 \\
Syracuse & 1991 \\
Temple & 1991 \\
Virginia Tech & 1991 \\
West Virginia & 1991 \\
\hline
\end{tabular}

Source: "Membership Timeline...," (n.d.).

We utilized three methods of assessing competitive balance. The first is the standard deviation of winning percentages, which measures the dispersion of winning percentages for conference games around the overall average, which will always be .500 . The formula for the standard deviation is:

$$
\sigma=\frac{\sqrt{ } \Sigma(\text { WPCT }-.500)^{2}}{N}
$$

The higher the standard deviation, the greater the dispersion of winning percentages around the mean. Accordingly, higher standard deviations are associated with lower levels of competitive balance, and lower standard deviations are linked with higher levels of competitive balance.

The second method we employed is the HirfindahlHirschman Index (HHI), which was originally designed to measure concentration among firms within an industry (Leeds \& von Allmen, 2005). The HHI may be adapted to measure the concentration of championships within a given sport over time. The formula for the HHI follows, with $f$ standing for the number of times each team in the conference wins a championship in a given time period and $\mathrm{T}$ standing for the number of years in that time period. 


$$
\mathrm{HHI}=\frac{\Sigma \mathrm{f}^{2}}{\mathrm{~T}}
$$

If for instance, 10 different teams win a championship in a given sport over a 10 -year period, the HHI would be 1.00 . If just one team won all 10 titles over that same period, the HHI would be 10.00 . Accordingly, the lower the HHI value, the better the competitive balance.

The third tool we used to evaluate competitive balance was the range of winning percentages for members of the conference during each time period. Winning percentages near .500 for conference games are indicative of better competitive balance. We set .500 plus or minus .100 as a range that would suggest a high degree of competitive balance over each time period. This range has been utilized in a previous published study on competitive balance within college football (Perline \& Stoldt, 2007).

\section{Results}

The following sections provide the results of the study based on the methods of assessing competitive balance described above.

\section{The ACC}

The following sections provide the results of the study based on the three methods of analyzing competitive balance described above.

Standard Deviation of Winning Percentages. Tables 3 and 4 display the winning percentages for the ACC for the years 19992003 and 2005-2011 respectively. Table 5 displays the standard deviations of winning percentages for all three time periods. As indicated in Table 5, the standard deviation was 0.253 for the 19992003 period and 0.228 for the $2005-11$ period. The lower standard deviation for the latter period would indicate an improvement in competitive balance after the addition of the three new members. 
Stoldt, Perline \& Vermillion

Table 3

ACC: Winning Percentage for Football Teams, 1999 through 2003

\begin{tabular}{cccccccccc}
\hline Year & FSU & UNC & UV & GTI & CU & NCSU & WFU & UM & DU \\
\hline 1999 & 1 & 0.25 & 0.625 & 0.625 & 0.625 & 0.375 & 0.375 & 0.25 & 0.375 \\
2000 & 1 & 0.375 & 0.625 & 0.75 & 0.75 & 0.5 & 0.125 & 0.375 & 0 \\
2001 & 0.75 & 0.625 & 0.375 & 0.5 & 0.5 & 0.5 & 0.375 & 0.875 & 0 \\
2002 & 0.875 & 0.125 & 0.75 & 0.5 & 0.5 & 0.625 & 0.375 & 0.75 & 0 \\
2003 & 0.875 & 0.125 & 0.5 & 0.5 & 0.625 & 0.5 & 0.375 & 0.75 & 0.25 \\
Mean & 0.9 & 0.3 & 0.575 & 0.575 & 0.6 & 0.5 & 0.325 & 0.6 & 0.125 \\
\hline
\end{tabular}

Table 4

ACC: Winning Percentage for Football Teams, 2005 through 2011

\begin{tabular}{ccccccccccccc} 
Year & FSU & UNC & UV & GTI & CU & NCSU & WFU & UM & DU & BC & VPI & UM \\
\hline 2005 & 0.625 & 0.5 & 0.375 & 0.625 & 0.5 & 0.375 & 0.375 & 0.375 & 0 & 0.625 & 0.875 & 0.75 \\
2006 & 0.375 & 0.25 & 0.5 & 0.875 & 0.625 & 0.25 & 0.75 & 0.625 & 0 & 0.625 & 0.75 & 0.375 \\
2007 & 0.5 & 0.375 & 0.75 & 0.5 & 0.625 & 0.375 & 0.625 & 0.375 & 0 & 0.75 & 0.875 & 0.25 \\
2008 & 0.625 & 0.5 & 0.375 & 0.625 & 0.5 & 0.5 & 0.5 & 0.5 & 0.125 & 0.625 & 0.625 & 0.5 \\
2009 & 0.5 & 0.5 & 0.25 & 0.875 & 0.75 & 0.25 & 0.375 & 0.125 & 0.375 & 0.625 & 0.75 & 0.625 \\
2010 & 0.75 & 0.5 & 0.125 & 0.5 & 0.5 & 0.625 & 0.125 & 0.625 & 0.125 & 0.5 & 1 & 0.625 \\
2011 & 0.625 & 0.375 & 0.625 & 0.625 & 0.75 & 0.5 & 0.625 & 0.125 & 0.125 & 0.375 & 0.875 & 0.375 \\
Mean & 0.571 & 0.429 & 0.29 & 0.66 & 0.607 & 0.411 & 0.482 & 0.393 & 0.107 & 0.589 & 0.821 & 0.5 \\
\hline
\end{tabular}

Table 5

\begin{tabular}{ll} 
ACC: Standard Deviation for Winning Percentages \\
\cline { 1 - 2 } Year & SD \\
\hline 1999 & 0.242 \\
2000 & 0.319 \\
2001 & 0.250 \\
2002 & 0.222 \\
2003 & 0.233 \\
Mean SD (99-03) & 0.253 \\
& \\
2005 & 0.226 \\
2006 & 0.255 \\
2007 & 0.244 \\
2008 & 0.141 \\
2009 & 0.232 \\
2010 & 0.267 \\
2011 & 0.232 \\
Mean SD (05-11) & 0.228 \\
\hline
\end{tabular}

Note: 2004 is omitted from our analysis because it was a year of membership transition between periods of membership stability. 
HHI Championship. Using the data from Tables 3 and 4 to construct the HHI to measure competitive balance between the two periods, again we found more competitive balance in the 2005-11 period than in the earlier period. Table 6 lists the conference champions by year based on our calculations. When we measured the regular season standings in the 1999-03 period we found Florida State won the championship four times, while Maryland won once (2001).

$\mathrm{HHI}=4^{2}+1^{2}=16+1=17 / 5=3.4$

Table 6

ACC: Regular Season Conference Champions, 1999-2003, 2005-2011

\begin{tabular}{lc}
\hline Year & Champion(s) \\
\hline 1999 & Florida State \\
2000 & Florida State \\
2001 & Maryland \\
2002 & Florida State \\
2003 & Florida State \\
2005 & Virginia Tech \\
2006 & Georgia Tech \\
2007 & Virginia Tech \\
2008 & BC, FSU, GTI, VPI \\
2009 & Georgia Tech \\
2010 & Virginia Tech \\
2011 & Virginia Tech
\end{tabular}

Note: 2004 is omitted from our analysis because it was a year of membership transition between periods of membership stability.

When measuring the HHI in the 2005-11 period we found that Virginia Tech won the outright championship four times and Georgia Tech did so twice. In 2008 there was a four-way tie among Boston College, Florida State, Virginia Tech and Georgia Tech.

Giving the whole point for an outright championship and .25 for the four-way tie, we found:

$\mathrm{HHI}=4^{2}+2.25^{2}+.25^{2}+.25^{2}+.25^{2}=16+5.06+.063+.063+.063$ $=21.25 / 7=3.04$ 
Given the fact that the lower the HHI, the more competitive balance, we can conclude that there was more competitive balance in the 2005-11 time period than in the earlier period.

Range of Winning Percentage. Setting .500 plus or minus .100 as a range which would suggest a high degree of competitive balance over each time period, we again find more competitive balance after realignment in the ACC. Table 3 indicates that in the 1999-2003 period, five of the nine member institutions $(55.6 \%)$ met this criteria. Table 4 indicates that after realignment in the 2005-11 period six institutions $(50.0 \%)$ of the expanded twelve member conference met the criteria. This would suggest that there was slightly more competitive balance in the ACC prior to realignment. Our conclusion, however, is based on the majority of measures and it points to more competitive balance in the latter time period.

\section{The Big East}

The following sections provide the results of the study based on the three methods of analyzing competitive balance.

Standard Deviation of Winning Percentages. Tables 7 and 8 display the winning percentages for the Big East for the years 1999-2003 and 2005-11 respectively. Table 9 displays the standard deviations for both time periods. As shown in the Table 9, the mean standard deviation in the 1999-2003 period was .301, and in the 2005-11 period was .243. Given the standard deviation was lower in the later period, it is apparent that there was more competitive balance in the 2005-11 period.

Table 7

Big East: Winning Percentage for Football Teams, 1999 through 2003

\begin{tabular}{ccccccccc}
\hline Year & UM & WVU & PU & VPI & BC & SU & RU & TU \\
\hline 1999 & 0.857 & 0.429 & 0.286 & 1 & 0.571 & 0.429 & 0.143 & 0.286 \\
2000 & 1.00 & 0.429 & 0.571 & 0.857 & 0.429 & 0.571 & 0 & 0.143 \\
2001 & 1.00 & 0.143 & 0.571 & 0.571 & 0.571 & 0.857 & 0 & 0.286 \\
2002 & 1.00 & 0.857 & 0.714 & 0.429 & 0.429 & 0.286 & 0 & 0.286 \\
2003 & 0.857 & 0.857 & 0.714 & 0.571 & 0.429 & 0.286 & 0.286 & 0 \\
Mean & 0.943 & 0.543 & 0.571 & 0.686 & 0.486 & 0.486 & 0.086 & 0.200 \\
\hline
\end{tabular}

Table 8

Big East: Winning Percentage for Football Teams, 2005 through 2011 


\begin{tabular}{ccccccccc}
\hline Year & WVU & UL & RU & USF & PU & UConn & CinU & SU \\
\hline 2005 & 1.000 & 0.714 & 0.571 & 0.571 & 0.571 & 0.286 & 0.286 & 0 \\
2006 & 0.714 & 0.857 & 0.714 & 0.571 & 0.286 & 0.143 & 0.571 & 0.143 \\
2007 & 0.714 & 0.429 & 0.429 & 0.571 & 0.429 & 0.714 & 0.571 & 0.143 \\
2008 & 0.714 & 0.143 & 0.714 & 0.286 & 0.714 & 0.429 & 0.857 & 0.143 \\
2009 & 0.714 & 0.143 & 0.429 & 0.429 & 0.714 & 0.429 & 1.000 & 0.143 \\
2010 & 0.714 & 0.429 & 0.143 & 0.429 & 0.714 & 0.714 & 0.286 & 0.571 \\
2011 & 0.714 & 0.714 & 0.571 & 0.143 & 0.571 & 0.429 & 0.714 & 0.143 \\
Mean & 0.754 & 0.489 & 0.510 & 0.429 & 0.571 & 0.449 & 0.612 & 0.184 \\
\hline
\end{tabular}

Table 9

Big East: Standard Deviation for Winning Percentages

\begin{tabular}{ll}
\hline Year & SD \\
\hline 1999 & 0.276 \\
2000 & 0.311 \\
2001 & 0.319 \\
2002 & 0.311 \\
2003 & 0.286 \\
Mean SD (99-03) & 0.301 \\
& \\
2005 & 0.286 \\
2006 & 0.257 \\
2007 & 0.175 \\
2008 & 0.277 \\
2009 & 0.276 \\
2010 & 0.202 \\
2011 & 0.226 \\
Mean SD (05-11) & 0.243
\end{tabular}

Note: 2004 is omitted from our analysis because it was a year of membership transition between periods of membership stability.

HHI Championships. Using the data from Tables 7 and 8 to construct the HHI to measure competitive balance between the two periods, again we found more competitive balance in the 2005-11 period than in the earlier period. Table 10 lists the conference champions by year based on our calculations. When we measured the regular season standing in the 1999-2003 period we found Miami was the outright champion three times, Virginia Tech was the champion once, and in one instance Miami and West Virginia shared the championship (2003). 
$\mathrm{HHI}=3.5^{2}+1^{2}+.5^{2}=12.25+1+.25=13.50 / 5=2.7$

Table 10

Big East: Regular Season Conference Champions, 1999-2003, 2005-2011

\begin{tabular}{cc}
\hline Year & Champion(s) \\
\hline 1999 & Virginia Tech \\
2000 & Miami \\
2001 & Miami \\
2002 & Miami \\
2003 & Miami, West Virginia \\
2005 & West Virginia \\
2006 & Louisville \\
2007 & UConn, West Virginia \\
2008 & Cincinnati \\
2009 & Cincinnati \\
2010 & UConn, Pitt, West Virginia \\
2011 & Cincinnati, Louisville, West Virginia \\
\hline
\end{tabular}

Note: 2004 is omitted from our analysis because it was a year of membership transition between periods of membership stability.

When we measured the HHI in the 2005-11 period we found that Cincinnati won the championship twice, West Virginia and

Louisville won once, and in three years $(2007,2010$, and 2011) there were multiple ties for the championship. In 2007 there was a twoway tie, and in 2010 and 2011 a three-way tie. Giving a whole point for an outright championship, .5 for a two-way tie, and .33 for a three-way tie, we found:

$\mathrm{HHI}=2.33^{2}+2.16^{2}+1.33^{2}+.833^{2}+.33^{2}=$ $5.42+4.67+1.77+.694+.109 / 7=1.81$

Given the fact that the lower the HHI, the more competitive balance, we can conclude that there was more competitive balance in the 2005-11 period than in the earlier period.

Range of Winning Percentage. Again, setting .500 plus or minus .100 as a range which would suggest a high degree of competitive balance over each period, we find more competitive 
balance after realignment in the Big East. In this case the data in Table 7 indicate that in the period before realignment (1999-2003) four of the eight institutions $(50 \%)$ met this criteria. After realignment in the 2005-11 period those within this range increased to five of the eight member institutions $(62.5 \%)$.

It can be concluded that the competitive balance in Big East football improved after the addition of Connecticut, Cincinnati, South Florida, and Louisville. This reinforces the results of other research that examined the effects of conference realignment on competitive balance in football.

\section{Discussion}

The conclusion that competitive balance in ACC and Big East football was better after changes in conference membership align the findings of this study with other research examining the effects of conference membership changes on competitive balance in football. Rhoads (2004) examined the Western Athletic and Mountain West Conferences and found improved competitive balance after member churning. Perline and Stoldt (2007) compared the later years of the Big 8 with the early years of the Big 12 and found improved levels of competitive balance after the Big 8 added four members formerly in the Southwest Conference. Perline et al. (2011) found slightly higher levels of competitive balance in Conference USA football after a recent round of churning.

The findings of each of these studies support the contention that football is a primary consideration in conference realignment decisions (Fort \& Quirk, 1999). If competitive balance is indeed a central concern for college athletic conferences (Rhoads, 2004; Staurowsky \& Abney, 2001), then it is reasonable to expect that higher levels of competitive balance in that important sport will be found following conference realignment.

Recent developments in conference realignment, specifically announced moves by Maryland and Rutgers to the Big 10, have been largely driven by the opportunity for conferences to expand their geographic footprint to new major television markets (Eisenberg, 2012). However, even in a television-driven climate, competitive balance remains a valid consideration. Anticipated viewership drives 
the value of television rights agreements, and uncertainty of outcome, a result of competitive balance, has been found to positively impact television ratings for football (Paul \& Weinbach, 2007). As a result, competitive balance seems likely to be a key issue for college athletics administrators, particularly at the NCAA I FBS level, for some time to come. 


\section{References}

Atlantic Coast Conference. (2013). This is the ACC. Retrieved from http://www.theacc.com/this-is/acc-this-is.html

Bennett, R.W., \& Fizel, J.L. (1995). Telecast deregulation and competitive balance: Regarding NCAA Division I football. American Journal of Economics and Sociology, 54 (2), 183 199.

Big East Conference. (n.d.a.). About the Big East. Retrieved from http://www.bigeast.org/AbouttheBIGEAST.aspx

Big East Conference. (n.d.b.). Big East Conference members: Present to 2015. Retrieved from http://www.bigeast.org/AbouttheBIGEAST/FutureMembersh ip.aspx

Caro, C.A. \& Benton, C.F. (2012). The great divide: Examining football revenue among FBS schools. International Journal of Sports Science \& Coaching, 7, 345-369.

Depken II, C.A., \& Wilson, D. (2004). The impact of cartel enforcement in NCAA IA football. In Fizel, J., \& Fort, R. (Eds). The economics of college sport (pp. 225-244). Westport, CT: Praeger.

Depken II, C.A., \& Wilson, D. (2006). NCAA enforcement and competitive balance in college football. The Southern Economic Journal, 72, 826-845.

Depken II, C.A. (n.d.). Realignment and profitability in Division IA college football. Unpublished paper. Retrieved from http://belkcollegeofbusiness.uncc.edu/cdepken/papers.html 
Depken II, C.A., \& Wilson, D. (n.d). The uncertainty outcome hypothesis in college football. Department of Economics, University of Texas-Arlington. Retrieved from http://belkcollegeofbusiness.uncc.edu/cdepken/papers.html

Dinich, H. (2012, June 27). Playoff plan to run through 2025. Retrieved from http://espn.go.com/collegefootball/story//id/8099187/ncaa-presidents-approve-fourteam-college-football-playoff-beginning-2014

Dittmore, S. W., \& Crow, C. M. (2010). The influence of the Bowl Championship Series on competitive balance in college football. Journal of Sport Administration \& Supervision, 2(1), 7-19.

Dodd, D. (2012, December 17). Source: Notre Dame, ACC safe from another Big 10 raid for now. Retrieved from http://www.cbssports.com/collegefootball/blog/dennis$\operatorname{dodd} / 21415170 /$ source-notre-dame-acc-safe-from-anotherbig-ten-raid-for-now

Eckard, E.W. (1998). The NCAA cartel and competitive balance in college football. Review of Industrial Organization, 13, 347369.

Eisenberg, J. (2012, November 19). Cash-strapped Maryland chooses Big 10 TV money over ACC tradition. Retrieved from http://sports.yahoo.com/blogs/ncaab-the-dagger/cashstrapped-maryland-must-weigh-whether-big-ten-155804159-ncaab.html

ESPN. (n.d.) College athletic conferences. Retrieved from http://espn.go.com/college-football/conferences

ESPN. (2012, July 19). Big East drops suit vs. TCU. Retrieved from http://espn.go.com/college-sports/story/_id/8179011/bigeast-drops-lawsuit-filed-texas-christian-horned-frogs 
Fort, R. \& Quirk, J. (1999). The college football industry. In J. Fizel, E. Gustafson \& L. Hadley (Eds.) Sports economics: Current research (pp. 11-26). Westport, CT: Praeger.

Fowler, J. (2013a, January 31). Details of San Diego State's contract with the Mountain West. Retrieved from http://www.cbssports.com/collegefootball/blog/jeremyfowler/21626589/details-of-san-diego-states-contract-withmountain-west

Fowler, J. (2013b, February 1). Big East-Catholic 7 documents note $\$ 68.8$ million in realignment funds. Retrieved from http://www.cbssports.com/collegefootball/blog/jeremyfowler/21628062/big-east-catholic-7-documents-note-688million-in-realignment-funds

Grant, R.R., Leadley, J., \& Zygmont, Z. (2008). The economics of intercollegiate sports. Mountain View, CA: World Scientific.

Hall, N. (2013, January 4). ACC comes out of realignment game quite a bit stronger. Retrieved from http://www.carolinacoastonline.com/news_times/sports/articl e_d6941ea4-5683-11e2-a61f-001a4bcf887a.html

Halliburton, S. (2011, Aug. 31). Texas A\&M leaves the Big 12. Retrieved from http://www.statesman.com/sports/collegefootball/texas-a-mleaves-big-12-1809226.html

Himmelsbach, A. (2012, November 29). ACC votes to add Louisville. USA Today. Retrieved from http://www.usatoday.com/story/sports/ncaab/2012/11/28/loui sville-acc-big-east-rick-pitino/1731501/ 
Humphreys, B. (2002). Alternative measures of competitive balance. Journal of Sports Economics, 3, (2), 133-148.

Leeds, M. \& von Allmen, P. (2005).The Economics of Sports.Boston: Pearson-Addison Wesley.

McMurphy, B. (2012, October 12). Navy won't join Big East early. Retrieved from http://espn.go.com/collegefootball/story/_id/8492730/navy-midshipmen-athleticdirector-says-academy-not-join-big-east-2015

McMurphy, B., \& O’Neil, D. (2012, November 20). Maryland accepts Big 10 invite. Retrieved from http://espn.go.com/collegesports/story/_id/8651934/maryland-terrapins-join-big-tenrutgers-scarlet-knights-join-well-sources-say

Membership timeline of the Big East conference. (n.d.). Orlando Sentinel. Retrieved from http://www.orlandosentinel.com/sports/college/knights/osbig-east-timeline-graphic-120711,0,3728749.htmlpage

Mitchell, K. (2011, October 26). Part one: 5 reasons you can't blame conference realignment. Retrieved from http://www.examiner.com/article/part-one-5-reasons-youcan-t-blame-conference-realignment

NBC Sports (n.d.). History of conference realignment. Retrieved from http://nbcsports.msnbc.com/id/37689691/

NCAA Division I conference realignment chart. (2012, July 19). Retrieved from http://csnbbs.com/showthread.php?tid $=567087$ 
NewsCore. (2012, May 18). Report: Boise St. set on Big East move. Retrieved from http://www.statesman.com/sports/collegefootball/texas-a-mleaves-big-12-1809226.html

Paul, R.J., \& Weinbach, A.P. (2007). The uncertainty of outcome and scoring effects on Nielsen ratings for Monday Night Football. Journal of Economics and Business, 59(3), 199211.

Perline, M.M. \& Stoldt, G.C. (2007). Competitive balance and conference realignment: The case of Big 12 football. The Sport Journal, 10 (2). http://www.thesportjournal.org/2007Journal/Vol10No2/Perline08.asp

Perline, M., Stoldt, G.C., \& Vermillion, M. (2011). Competitive balance in Conference USA football: The effects of membership churning. Manuscript submitted for publication.

Perline, M., Stoldt, G.C., \& Vermillion, M (2013, January 16). Member churning among conferences: A contributing factor to economic inequality. Poster presentation at the National Collegiate Athletic Association Scholarly Colloquium, Grapevine, TX.

Rein, I., Kotler, P., \& Shields, B. (2006). The elusive fan. New York: McGraw-Hill.

Rhoads, T.A. (2004). Competitive balance and conference realignment in the NCAA. Paper presented at the $74^{\text {th }}$ Annual Meeting of Southern Economic Association, New Orleans, LA. 
Smith, E. (2012, July 16). Syracuse reaches deal with Big East to join ACC early. USA Today. Retrieved from http://content.usatoday.com/communities/campusrivalry/post /2012/07/syracuse-joining-acc-early-big-east-exitpittsburgh/1\#.UCqdlkJOTdk

Staurowsky, E.J. \& Abney, R. (2011). Intercollegiate athletics. In P.M. Pedersen, J.B. Parks, J. Quarterman, \& L. Thibault (Eds.) Contemporary sport management (4 ${ }^{\text {th }}$ ed., pp. 142163). Champaign, IL: Human Kinetics.

Sutter, D., \& Winkler, S. (2003). NCAA scholarship limits and competitive balance in college football. Journal of Sports Economics, 4 (1), 3-18.

Thamel, P. (2011, September 19). With big paydays at stake, college teams scramble for a spot. New York Times. Retrieved from http://www.nytimes.com/2011/09/20/sports/ncaafootball/inconference-realignment-colleges-run-topaydaylight.html?pagewanted $=$ all

Wieberg, S. \& Berkowitz, S. (2011, November 1). Is ESPN the main force behind realignment in college sports? USA Today. Retrieved from http://www.usatoday.com/sports/college/story/2011-10-27/isespn-the-force-behind-college-conferencerealignment/51019966/1

Wolken, D. (2012, December 31). Analysis: Windfall for Boise State, freefall for Big East? USA Today. Retrieved from http://www.usatoday.com/story/sports/ncaaf/mwest/2012/12/ 31/boise-state-mountain-west-big-east-analysis/1801707/ 
The Journal of SPORT, 2013, 2(2), 154-174

(C) Kent State University

\title{
A Preliminary Investigation of Job Satisfaction of Compliance Officers at NCAA Division II institutions
}

\author{
Jennifer Parsons \\ Ashland University \\ Lance P. Kaltenbaugh \\ Ashland University \\ Ken Brubaker \\ Ashland University \\ Bryce Winters \\ Ashland University \\ Sabrina Cali \\ Cleveland State University
}

\begin{abstract}
Identifying what job characteristics influence employee satisfaction requires the ability to effectively study the environment that influences the sense of belonging and a fulfillment of social needs. The primary purpose of this study was to investigate aspects of employment that influence job satisfaction of NCAA Division II compliance officers. Job satisfaction was measured by the Job Satisfaction Survey (JSS), which consisted of nine subscale measures that relate to employee job satisfaction and strongly examines perceptual and attitudinal variables (Spector, 1997). Participants for this study consisted of 206 NCAA Division II compliance officers. Descriptive analysis was conducted to determine to what degree NCAA Division II compliance officers express their job satisfaction. Results suggested that supervision, co-workers, and nature of work were the three highest-ranking measures of job satisfaction. The compliance officers appeared satisfied when given autonomy over their job, played a greater role in organizing the environment of intercollegiate athletics and had productive work relationships with athletic staff.
\end{abstract}




\section{Introduction}

For over a century, critics have condemned the substantial athletic budgets compared to meager academic departments' resources, the scandals associated with athletes' grade manipulation or outright cheating, the exploitation of the athletes, and the big business mentality leading to a win-at-all-cost attitude at many institutions of higher learning (Beyer \& Hannah, 2000). In some instances, powerful alumni donors and athletic directors would "dominate weak presidents, disorganized faculties, and powerless students" (Sojka, 1983, p. 58), while strongly encouraging interest in and support of their athletic teams as a means of creating national recognition and prestige.

From its inception in 1905, the National Collegiate Athletic Association (NCAA) has adopted thousands of rules and regulations to protect the student-athletes and prevent unethical advantages (Covell \& Barr, 2001). Many of the initial rules focused on consistency in eligibility across institutions. In the late 1970s and early 1980s, there was a call for reform to increase the academic performance of athletes (Covell \& Barr, 2001). Perhaps the most noted changes occurred after abysmal athlete graduation rates (less than $50 \%$ in football) were publicized in the early 1980 s (Heck \& Takahashi, 2006). Despite instituting new rules and harsh penalties, scandals involving college athletes have continued to make headlines.

The NCAA develops and implements regulations for all levels of competition (Division I, II, III) in areas varying from graduation rates to eligibility to improper benefits (NCAA.org) The vast array of NCAA bylaws, rules and regulations are monitored by each member institution's department or division of compliance. The compliance officer is responsible for monitoring, reporting, and enforcing the NCAA bylaws at his/her institution (Kihl, 2009). Compliance officers are also involved in other aspects of athletic programs from marketing, development, budget, strength and conditioning and coaching (Copeland, 2008). Furthermore, The National Association of Athletics Compliance (NAAC) exists to give compliance directors a greater role in organizing the environment of intercollegiate athletics. The NAAC helps compliance professionals 
by providing compliance solutions on behalf of college athletics (Copeland). Annually, the NAAC holds a national convention that focuses on professional development and provides the opportunity for athletic directors to discuss key issues and concerns within collegiate sports. One of the NAAC's focus points in past years has been to develop standards for professionals to hire well-qualified and prepared compliance administration.

In addition to possessing a thorough understanding of the latest NCAA rules manual and being familiar with the NAAC guidelines, the compliance officer also must report infractions that could ultimately jeopardize the success of an athletic program and tarnish the reputation of an institution. As stated by Pierce, Kaburakis, and Fielding (2008), "Coaches need to win, whereas compliance officers need coaches to abide by the rules" (p. 87). Due to changes in coaching tenure and the need for a winning season to hold one's job, these factors can impact the chances for behavior that violates NCAA rules. As a result, the role of the compliance officer is incredibly important and demanding.

\section{Job Satisfaction}

Within institutional, industrial, and social psychology research, the concept of job satisfaction is a central research theme (Bardett \& Weeks, 2005; Henne \& Locke, 1985) and is viewed as a goal of organizations (Balzer, Kihm, Smith, Bachlochi, Robie, \& Parra, 1997; Locke, 1976). As research continues to examine the complex and dynamic process of job satisfaction, there is a sustained attempt to investigate and define the various definitions of job satisfaction in the literature (Henning \& Terranova, 2011; Pettit, Goris, \& Vaught, 1997). Locke (1976) was one of the first researchers to define job satisfaction as "a pleasurable or positive emotional state resulting from the appraisal of one's job or job experiences" (p. 1300). Later work by Locke and Latham (1990) simplified the definition of job satisfaction as the favorableness or unfavorableness with which employees view their work. Balzar et al. (1997) refined the definition of job satisfaction as feelings that employees have regarding their work environment and their expectations towards work. Thus, job satisfaction can be recognized 
as what one wants or values from a job (Brief \& Weiss, 2002). These authors suggested that in any job the way in which an employee viewed his or her work influenced the amount of satisfaction (morale) he or she received from the job (Heyle, 2007; Spector, 1997).

Identifying what job characteristics made employees satisfied required the ability to effectively study the environment that influenced the sense of belonging and a fulfillment of social needs. These factors are conducive to a quality work life. Previous research has suggested that the work environment can have a major influence on job satisfaction (Kulhavy \& Schwartz, 1981; Llorente \& Macias, 2005). Gordon, Anderson, and Bruning (1992), added that institutions also have a responsibility to commit themselves to their employees' welfare, rights, and product quality. Being able to link characteristics of work identity with specific job characteristics serves as important antecedents of job satisfaction.

\section{Work Environment}

The role a positive work environment played in job satisfaction has also been examined. The prevailing argument by Morrison (2002) was that organizations must be responsive to not only providing a job and income, but a constructive work environment as well. Carlson and Mellor (2004) stated that "satisfaction is expected when a job allows an incumbent to be engaged in intrinsic forms of self-expression" (p. 238). Simply put, employees who were engaged in work practices were more likely to develop the positive beliefs and attitudes associated with employee engagement, enhanced performance, and job satisfaction.

Further research suggested that when employees were content with their organization, they felt their work and contributions were valuable assets and would, to a certain extent, influence the amount of satisfaction (morale) they received from the job (Eisenberger, Fasolo, \& Davis-LaMastro, 1990; Pettit et al., 1997). King, Lahiff, and Hatfield (1988) reported that there was a "consistently clear and positive pattern of relationships between an employee's perceptions of their work and his or her job satisfaction" (p. 36). Thus, employees who were able to improve their work 
experience often enhanced their overall well-being and were most likely to succeed (Brown \& Mitchell, 1993; Eisenberg \& Goodall, 2004; Sias, 2005; Wheatley, 2001).

\section{Employee Motivation}

A growing body of research investigated employees' work and motives and how it explained satisfaction with the job (C. M. Anderson \& Martin, 1995). Zhang, DeMichele, and Connaughton (2004) suggested that certain motivational factors contributed to job satisfaction such as "achievement, recognition, work itself, responsibility, advancement, and professional growth" (p. 187).

Likewise, there were positive correlations between job satisfaction and an employees' mental well-being, commitment to the job, and motivational factors (Kreitner \& Kinicki, 2006). King et al. (1988) also reported that there was a "consistently clear and positive pattern of relationships between an employee's perceptions of their job duties and responsibilities and his or her job satisfaction" (p. 36). Studies demonstrated that when people's needs were met through a satisfying work environment they were more likely to remain at their job and experience satisfaction (Rubin, 1993). Conversely, unfulfilled needs resulted in counterproductive work behaviors and high degrees of dissatisfaction with their job (R. B. Rubin \& Rubin, 1992), which contributed to feelings of dissatisfaction with superiors, job duties and responsibilities, and ultimately the institution (Jablin \& Krone, 1994). Finally, Zhang et al. (2004) agreed that job satisfaction was not merely an employee's responsibility but an organization's ability to satisfy the "needs, values, and expectations of employees" (p. 187). Various factors that may influence whether an individual leaves a career, but job satisfaction has been an indicator in regards to staying or leaving a profession or organization.

\section{Challenges for Compliance Officers}

Administrators in Higher Education are realizing that employees cannot be taken for granted. Institutions are dealing with employees who look for job satisfaction, who believe in personal options and independence, and who want meaningful work 
(D’Aprix, 1996). Previous research suggested that a meaningful work environment increased job satisfaction (D’Aprix, 1996; Downs, Clampitt, and Pfeiffer, 1988; Pettit et al., 1997; Pincus, 1986; Sias, 2005). Similar findings suggested there were various organizational and individual work environment variables such as "internal communication, organizational structure, political climate, participation in decision making, independence, benefits, and job effectiveness" (Zhang et al., 2004, p. 188) that provided increased levels of satisfaction with one's work. These variables would apply to the work environment of NCAA compliance officers.

With the heightened awareness of adhering to the rules and regulations set forth by the NCAA, not providing a work environment conducive to a high level of job satisfaction could ultimately impact the overall compliance of an athletic department. For example, lack of motivation stemming from limited opportunities for advancement or lack of recognition from superiors and co-workers, could lead to minimal effort to complete the necessary paperwork or follow-up on potential violations. With many NCAA Division II compliance officers having other work responsibilities, the worst-case scenario may be a sense of apathy with their role as compliance officer compared to more personally rewarding positions they also hold. To better understand the role job satisfaction plays in institutional compliance, more research is warranted.

\section{Purpose of the Study}

Research assessing job satisfaction and work environment on college campuses has been performed. Studies examining college and university presidents (Perrakis, Galloway, Hayes, \& RobinsonGaldo, 2011), faculty members (Bozeman \& Gaugahan, 2011; Marston \& Brunetti, 2009) and campus recreation professionals (Kaltenbaugh, 2009; Stier, Schneider, Kampf, \& Gaskins, 2010) suggest that work environment may play a role in the participants' overall satisfaction.

Although NCAA Division I compliance has garnered frontpage attention, the position of compliance officer has received little consideration with regard to job satisfaction. To handle the workload 
of compliance at Division I level, many institutions have entire departments devoted exclusively to monitoring coaches, athletes, and other individuals who fall under the NCAA rules and regulations. In stark contrast, the Division II compliance officer has limited resources and is often responsible for other areas in the athletic department such as coaching or administrative duties.

The majority of available research focuses exclusively on the Division I level. The purpose of this study is to provide an initial examination into the factors that influence the job satisfaction surrounding NCAA Division II compliance officers.

\section{Survey}

\section{Methods}

Participants completed a web-based version of the Job Satisfaction Survey (JSS) which measured nine facets of job satisfaction. The 36-item survey (Spector, 1985) included facets relating to pay, promotional opportunities, fringe benefits, contingent rewards, supervision, co-workers, nature of work, communication, and operating procedures. Respondents were asked to indicate their level of agreement using a 6-point Likert-type scale ranging from "strongly agree" to "strongly disagree."

\section{Subjects}

The accessible population of this study was 260 compliance officers at National Collegiate Athletic Association (NCAA) Division II institutions listed on the NCAA website (www.ncaa.com). A total of 134 surveys were returned resulting in a $52 \%$ response rate of useable data for purposes of data analysis. According to Krejcie and Morgan (1970) 125 respondents were needed to reach a 95 percent confidence level which substantiates the studies sample size. An additional 12 incomplete surveys were returned; these surveys were deemed unusable and were discarded.

A cover letter, explaining the purpose of the study, was included in the web-based version of the JSS which was sent to each institution's compliance officer (one survey per institution). Participants were asked to anonymously, and on a voluntary basis, fill out the online JSS through Survey Monkey. To preserve 
anonymity of the respondents, no identifying characteristics of the subjects were used. All information gathered was kept confidential. The data-collection process was completed in seven weeks from June to August 2012.

\section{Scale Properties - Reliability}

\section{Results}

The JSS (Spector, 1985) is a well-established instrument that has been repeatedly investigated for reliability and validity. Reliability results showed that 11 of the 12 subscales used to measure job satisfaction were above the minimum coefficient alpha of .70 (Fraenkel \& Wallen, 2003) and were deemed to be reliable. Operating procedures was the only subscale that did not meet the 0.70 coefficient alpha standard for internal consistency. Overall, the reliability of the nine subscales was 0.92 , well above the traditional cutoff.

\section{Descriptive Analysis of Job Satisfaction}

To interpret mean scores of the JSS, Spector (1994) uses an absolute approach. Since the JSS uses 6-point agree-disagree response choices, a mean score of 3.5 is the arbitrary cut score to represent dissatisfaction versus satisfaction. The survey data were analyzed descriptively with means, per the guidelines of the JSS. Means were used to answer what degree does NCAA Division II compliance officers express their job satisfaction. The content of the JSS investigated nine sub facets which included pay, promotional opportunities, fringe benefits, contingent rewards, supervision, coworkers, nature of work, communication, and work conditions.

Respondents were asked specific questions relating to their job. A mean score above the mid-point mean score of 3.5 indicates that participants were satisfied with their job and dissatisfied when below. As shown in Table 1, supervision $(\mathrm{M}=5.01)$ had the highest mean score whereas pay $(\mathrm{M}=2.93)$ had the lowest mean score. An overall score of 3.93 indicated that the respondents were satisfied with their job. The data indicated that supervision, fringe benefits, contingent rewards, co-workers, nature of work, and communication were above 3.5. Pay, promotion, and operating procedures were facets in which compliance officers scored below the scale's mean. 
Table 1 depicts the mean scores of the NCAA Division II compliance officer sample.

\begin{tabular}{|c|c|c|c|c|}
\hline JSS Sub Facets & Individual item & Mean & $\begin{array}{l}\text { Std. } \\
\text { Dev. }\end{array}$ & $\begin{array}{l}\text { Overall Sub } \\
\text { Facet Mean }\end{array}$ \\
\hline Pay & $\begin{array}{l}\text { I feel I am being paid a fair amount for the work } \\
\text { I do. } \\
\text { Raises are too few and far between. } \\
\text { I feel unappreciated by the organization when I } \\
\text { think about what they pay me. } \\
\text { I feel satisfied with my chances for salary } \\
\text { increases. }\end{array}$ & $\begin{array}{l}3.22 \\
2.22 \\
3.46 \\
2.81\end{array}$ & $\begin{array}{l}1.597 \\
1.470 \\
1.564\end{array}$ & 2.93 \\
\hline Promotion & $\begin{array}{l}\text { There is little chance for promotion at my job. } \\
\text { Those who do well on the job stand a fair } \\
\text { chance of being promoted. } \\
\text { People get ahead as fast here as they do in other } \\
\text { places. } \\
\text { I am satisfied with my chances for promotion. }\end{array}$ & $\begin{array}{l}3.06 \\
3.33 \\
2.92 \\
3.10\end{array}$ & $\begin{array}{l}1.574 \\
1.348 \\
1.208 \\
1.471\end{array}$ & 3.10 \\
\hline Supervisor & $\begin{array}{l}\text { My supervisor is quite competent in doing } \\
\text { his/her job. } \\
\text { My supervisor is unfair to me. } \\
\text { My supervisor shows little interest in the } \\
\text { feelings of subordinates. } \\
\text { I like my supervisor. }\end{array}$ & $\begin{array}{l}4.78 \\
5.25 \\
4.74 \\
5.25\end{array}$ & $\begin{array}{l}1.340 \\
1.122 \\
1.337 \\
.979\end{array}$ & 5.01 \\
\hline Fringe Benefits & $\begin{array}{l}\text { I am not satisfied with the benefits I receive. } \\
\text { The benefits we receive are as good as most } \\
\text { other organizations offer. } \\
\text { The benefit package we have is equitable. } \\
\text { There are benefits we do not have which we } \\
\text { should have. }\end{array}$ & $\begin{array}{l}4.19 \\
4.17 \\
4.38 \\
3.51\end{array}$ & $\begin{array}{l}1.537 \\
1.433 \\
1.225 \\
1.408\end{array}$ & 4.06 \\
\hline $\begin{array}{l}\text { Contingent } \\
\text { Rewards }\end{array}$ & $\begin{array}{l}\text { When I do a good job, I receive the recognition } \\
\text { for it that I should receive. } \\
\text { I do not feel that the work I do is appreciated. } \\
\text { There are few rewards for those who work here. } \\
\text { I don't feel my efforts are rewarded the way they } \\
\text { should be. }\end{array}$ & $\begin{array}{l}4.10 \\
3.89 \\
3.66 \\
3.34\end{array}$ & $\begin{array}{l}1.378 \\
1.535 \\
1.497 \\
1.441\end{array}$ & \\
\hline
\end{tabular}

\begin{tabular}{llll}
\hline Operating & Many of our rules and procedures make doing a & 3.47 & 1.434 \\
Conditions & $\begin{array}{l}\text { good job difficult. } \\
\text { My efforts to do a good job are seldom blocked }\end{array}$ & $3.77 \quad 1.476$ \\
& by red tape.
\end{tabular}




\begin{tabular}{|c|c|c|c|c|}
\hline & $\begin{array}{l}\text { I have too much to do at work. } \\
\text { I have too much paperwork. }\end{array}$ & $\begin{array}{l}2.40 \\
2.23\end{array}$ & $\begin{array}{l}1.158 \\
1.232\end{array}$ & 2.97 \\
\hline Co-Workers & $\begin{array}{l}\text { I like the people I work with. } \\
\text { I find I have to work harder at my job because } \\
\text { of the incompetence of people I work with. } \\
\text { I enjoy my coworkers. } \\
\text { There is too much bickering and fighting at } \\
\text { work. }\end{array}$ & $\begin{array}{l}5.31 \\
3.54 \\
5.15 \\
4.20\end{array}$ & $\begin{array}{l}.760 \\
1.454 \\
.854 \\
1.496\end{array}$ & 4.55 \\
\hline $\begin{array}{l}\text { Nature of } \\
\text { Work }\end{array}$ & $\begin{array}{l}\text { I sometimes feel my job is meaningless. } \\
\text { I like doing the things I do at work. } \\
\text { I feel a sense of pride in doing my job. } \\
\text { My job is enjoyable. }\end{array}$ & $\begin{array}{l}4.61 \\
4.87 \\
5.19 \\
4.84\end{array}$ & $\begin{array}{l}1.424 \\
1.116 \\
.943 \\
1.042\end{array}$ & 4.88 \\
\hline $\begin{array}{l}\text { Communi- } \\
\text { cation }\end{array}$ & $\begin{array}{l}\text { Communications seem good within this } \\
\text { organization. } \\
\text { The goals of this organization are not clear to } \\
\text { me. } \\
\text { I often feel that I do not know what is going on } \\
\text { with the organization. } \\
\text { Work assignments are not fully explained. }\end{array}$ & $\begin{array}{l}3.66 \\
4.46 \\
3.92\end{array}$ & $\begin{array}{l}1.360 \\
1.401 \\
1.436 \\
1.254\end{array}$ & 4.10 \\
\hline
\end{tabular}

\section{Contribution of Demographic Factors}

The subjects surveyed were NCAA Division II compliance officers. Demographics of the respondents revealed that $41 \%$ identified themselves as male, and $59 \%$ as female. As to the age of the subjects, $0.7 \%$ were under $25,45.5 \%$ were $26-35,22.4 \%$ were $36-45,22.4 \%$ were $46-55$, and $9 \%$ were 60 or older. Participation by type of institution was $51.5 \%$ public and $48.5 \%$ private. As to the student population of the institution, $77(57.5 \%)$ had less than 5,000 students; 47 (35.1\%) were between 5,001 and 15,000; 8 (6\%) between 15,001 and 25,000; $1(0.7 \%)$ between 25,001 and 40,000; and $1(0.7 \%)$ had over 40,000 . Regarding years in position, 46 $(34.3 \%)$ reported they had been working for the organization for more than 5 years, $40(29.9 \%)$ subjects between 3 and 5 years, 43 (32.1\%) subjects between 1 and 3 years, and the rest, $5(3.7 \%)$, had worked for the organization less than one year. Description of the participant demographic composition is presented in Table 2. 
Table 2 Demographic Characteristics of NCAA Division II Compliance Officers (N 134)

Characteristics Compliance Officers

\begin{tabular}{lrr}
\cline { 2 - 2 } & $\underline{\mathrm{n}}$ & $\underline{0}$ \\
& & \\
\hline & & \\
Gender & & \\
Male & 55 & 41.0 \\
Female & 79 & 59.0 \\
Age Classification & & \\
$18-25$ & 1 & 0.7 \\
$26-35$ & 61 & 22.4 \\
$36-45$ & 30 & 22.4 \\
$46-55$ & 30 & 9.0 \\
$60+$ & 12 & \\
& & 3.7 \\
Years in Position & & 32.1 \\
Less than 1 year & 5 & 29.9 \\
$2-3$ years & 43 & 34.3 \\
$4-5$ years & 40 & \\
More than 6 years & 46 &
\end{tabular}

\section{Discussion}

The current study presented an initial step in exploring the dynamics of job satisfaction as expressed by compliance officers of NCAA Division II institutions. The results indicated that the job dimensions for supervision, co-workers, and nature of work were the three highest scores above the mean. Items that measured fringe benefits and contingent rewards also had mean scores that scored above average in terms of job satisfaction. Based on the current findings pay, promotion, and operating conditions were below the mid-point of the scale. These three sub facets did not score as highly on the JSS, which could indicate areas in which these compliance officers were less satisfied with their job. 


\section{Supervision}

Compliance officers in this study reported more satisfaction with supervision than with any other facet of job satisfaction. Ryan, Clopton, and Irwin (2008) suggested that there was a highly significant relationship between supervisory support and job satisfaction. One of the many roles of an athletic director is to supervise the compliance officer's efforts to help ensure the department follows NCAA rules and regulations.

Participants reported favorably with supervision when they are provided the opportunity to have input into departmental policy issues. Work by Spector (1997) summarized that when employees participate in making decisions for the organization they feel supportive and respected. Since supervision scored positively among participants, athletic directors might be giving compliance officers the opportunity to make those important decisions that positively affect his or her work environment.

As stated by Spector (1985), the amount of autonomy given to employees had an effect on an employees' job satisfaction. The findings from the current study suggest that compliance officers value the level of autonomy in performing their job and would appear to appreciate appropriate supervision. An essential component of supervision seems to be that compliance officers are satisfied when they are given a greater role in organizing the environment of intercollegiate athletics. Having the autonomy to complete their day to day job experiences without much resistance could be one of the explanatory factors on participants' satisfaction with their job.

\section{Co-Workers}

Building productive relationships with co-workers can impact the degree of overall job satisfaction. Creating environments of trust and honesty while holding similar values may be the job of the athletic administration, but almost certainly influences the productivity and level of conflict within of the overall department (Kerwin \& Doherty, 2012). The level of communication and satisfaction with coworkers in this study appeared to have a positive influence on the overall attitude and satisfaction of the participants. 
Thus, compliance officers appreciated the relationships built with their coworkers.

Achieving and maintaining NCAA compliance requires input from many members of an athletic department. A compliance officer's level of job satisfaction is related to the relationships and the characteristics of the groups to which they belong. Previous research (Beehr, et al 2006; Holloway, 1995) indicated that employees who were able to develop effective interpersonal relationships with their peers reported being more satisfied with their co-worker and work conditions. A negative work environment could ultimately influence interaction with peers and co-workers having a significant impact on a compliance officer's attitude and behavior. Minimizing personal and professional conflicts within the athletic department personnel is likely to have an impact on not only the productivity of compliance initiatives, but also on the overall job satisfaction of the individuals involved.

\section{Nature of Work}

The current study indicated that respondents were satisfied with the nature of the work itself. According to Spector (1997) nature of work includes job challenges, variety and scope of work conditions, freedom to try new things, and other outcomes such as employee retention. These factors of a work environment must fit with the culture of an athletic department or division to increase job satisfaction, otherwise compliance officers and other employees may look elsewhere to find a workplace better suited to his or her needs.

A good working environment will not only help employees remain satisfied with what they do, but also enhance retention and future recruitment efforts (Kaltenbaugh, 2009). Employee turnover has been linked to lower job satisfaction regardless of industry (Long $\&$ Thean, 2011). Reducing turnover has been a noteworthy concern for any variety of organizations due to the important role of building an organization's human capital. Organizations can influence the work environment by providing appropriate training, adequate compensation and advancement opportunities, as well as monitoring the employees' level of satisfaction with their position (Kazi, Aziz, \& Zadeh, 2012). 
These factors would be no different for the position of compliance officer. Turnover of compliance officers could cost institutions in terms of time and money spent on training and recruitment as well as potentially gaps in reporting data to the NCAA. Knowing how to use a positive work environment to increase or maintain compliance officer's satisfaction and reduce turnover is a key to developing a high-performance workforce.

\section{Implications and Future Research}

The results of this study provide an initial examination into the job satisfaction of compliance officers within NCAA Division II member institutions. The findings add to the overall existing body of work in the job satisfaction field and advance the limited knowledge that pertains specifically to compliance officers' work environments. The role of the compliance officer in monitoring and enforcing rules is important to the overall success and reputation of the athletic department. The potential benefits stemming from providing a positive work environment are enhanced self-motivation, level of communication, and rapport with co-workers. In addition, these findings may provide some direction for athletic directors who are responsible for the hiring and supervision of compliance officers. By providing the needed support and avenues of communication, retention of compliance officers might be enhanced which would create continuity in reporting to the organization's governing body.

Although the present study used the Job Satisfaction Survey's nine variables to determine job satisfaction, various athletic directors and institutions might have different variables or research questionnaires to measure job satisfaction more effectively. Other factors or subscales may have a more direct impact on job satisfaction than those used for this study. It is important to state that the findings of this study may only be generalizable to the population of NCAA Division II athletic departments included in the study. An examination of those charged with compliance duties across all levels of athletic administration from interscholastic to professional and elite international athletic associations is also recommended. 
Finally, further research is needed to determine the underlying causes of why NCAA Division II compliance officers are satisfied or dissatisfied with their jobs. Are there specific experiences that can effect job satisfaction? If so, what would be the consequences of such experiences? In other words, what could potentially happen if compliance officers were not satisfied in their job (besides being personally unhappy)? Other avenues of research could investigate whether success of the school's athletic program, size of institution, lack of training, or job responsibilities has any correlation to a compliance officer's job satisfaction. 


\section{References}

Anderson, C. M., \& Martin, M. M. (1995). Why employees speak to coworkers and bosses: Motives, gender, and organizational satisfaction. Journal of Business Communication, 32(3), 249.

Balzer, W.K., Kihm, J.A., Smith, P.C., Irwin, J.L., Bachlochi, P.D., Robie, C., Parra, L. (1997). User's manual for the job descriptive index (JDI: 1997 revision) and the job in general scales. Bowling Green, Ohio: Bowling Green State University, Department of Psychology.

Bardett, K. R. \& Weeks, K.P. (2005). Turnover intentions and voluntary turnover: The moderating rolesof self- monitoring, locus of control, proactive personality, and risk aversion. The Journal of Applied Psychology, 90 (5), 980-990.

Beehr, T.A., Glaser, K.M., Beehr, M.J., Beehr, D.E., Wallwey, D.A., Erofeev, D.(2006). The nature of satisfaction with subordinates: Its predictors and importance to supervisors. Journal of Applied Social Psychology, 36(3), 1523-1547.

Beyer, J., \& Hannah, D. (2000). The cultural significance of athletics in U.S. higher education. Journal of Sport Management, 14(2), 105-132.

Bozeman, B., \& Gaughan, M. (2011). Job satisfaction among university faculty: individual, work, and institutional determinants. Journal Of Higher Education, 82(2), 154-186.

Brief, A. P., \& Weiss, H. M. (2002). Organizational behavior: Affect in the workplace. Annual Review Psychology, 53, 279-307.

Brown, K. A., \& Mitchell, T. R. (1993). Organizational obstacles: Links with financial performance, customer satisfaction, and job satisfaction in a service environment. Human Relations, $46,725-758$. 
Carlson, J. H., \& Mellor, S. (2004). Gender-related effects in the jobdesign-job- satisfaction relationship: An interactional approach. Sex Roles, 51(3/4), 237-247.

Copeland, J. (2008). New name, broader mission: Compliance pros step up. NCAA News, 1-3.

Covell, D., \& Barr, C. A. (2001). The ties that bind: Presidential involvement with the development of NCAA division I initial eligibility legislation. Journal of Higher Education, 72(4), 414-452.

D'Aprix, R. M. (1996). Communicating for change: Connecting the workplace with the marketplace. San Francisco: Jossey-Bass.

Downs, C., Clampitt, P., \& Pfeiffer, A. (1988). Communication and organizational outcomes. In G. Goldhaber \& G. Barnett (Eds.), Handbook of organizational communication (pp. 171211). Norwood, NJ: Ablex.

Eisenberg, E. M., \& Goodall, H. L., Jr. (2004). Organizational communication: Balancing creativity and constraint $\left(4^{\text {th }} \mathrm{ed}\right.$.). Boston: Beford/St. Martin's Press

Eisenberger, R., Fasolo, P., \& Davis-LaMastro, V. (1990). Perceived organizational support and employee diligence, commitment, and innovation. Journal of Applied Psychology, 75 (1), 5159.

Fraenkel, J., \& Wallen, N. (2003). How to design and evaluate research in education. New York: McGraw-Hill.

Gordon, W. I., Anderson, C. M., \& Bruning, S. D. (1992). Employee perceptions of corporate partnership: An affective-moral quid pro quo. Employee Responsibilities and Rights Journal, 5, $75-85$. 
Heck, R. H., \& Takahashi, R. (2006). Examining the impact of proposition 48 on graduation rates in division IA football and program recruiting behavior: Testing a policy change model. Educational Policy, 20(4), 587-614.

Henne, D., \& Locke, E. A. (1985). Job dissatisfaction: What are the consequences? International Journal of Psychology, 20, 221240 .

Henning, J.M. \& Terranova, A. B. (2011). National collegiate athletic association division and primary job title of athletic trainers and their job satisfaction or intention to leave athletic training. Journal of Athletic Training, 46(3), 321-318.

Heyle, L. E. (2007). An examination of the effect of job autonomy on job satisfaction. Proquest Dissertations and Theses. (UMI No. AAT 1441783)

Holloway, E.L. (1995). Clinical supervision: A systems approach. Research in Organizational Behavior, 2, 37-71.

Jablin, F. M., \& Krone, K. J. (1994). Task/work relationships: A life space perspective. In M. L. Knapp \& G. R. Miller (Eds.), Handbook of interpersonal communication (pp. 621-675). Thousand Oaks, CA: Sage.

Kaltenbaugh, L. (2009). A study on job satisfaction among campus recreation administrators at four-year public and private institutions. Recreational Sports Journal, 33(2), 89-101.

Kazi, G., Aziz, S., \& Zadeh, Z. F. (2012). The contribution of organizational variables and its impact on job turnover and job satisfaction of employee's. Interdisciplinary Journal Of Contemporary Research In Business, 3(10), 1067-1073. 
Kerwin, S., \& Doherty, A. (2012). An investigation of the conflict triggering process in intercollegiate athletic departments. Journal of Sport Management, 26(3), 224-236.

Kihl, L. (2009). Pacific-10 compliance officers' morality and moral reasoning. Journal of Issues in Intercollegiate Athletics, 2, 111-149.

King, W., Lahiff, J., \& Hatfield, J. (1988). A discrepancy theory of the relationship between communication and job satisfaction. Communication Research Reports, 5, 36-43.

Kulhavy, R. W., \& Schwartz, N. H. (1981). Tone of communication and climate perceptions. Journal of Business Communication, 18(1), 17-24.

Kreitner, R., \& Kinicki, A. (2006). Organizational Behavior. New York: McGraw Hill.

Krejcie, R. V. \& Morgan, D. W. (1970). Determining sample size for research activities. Educational Psychology Measures, 30(3), 607-610.

Llorente, R. M. B., \& Macias, E. F. (2005). Job satisfaction as an indicator of the quality of work. The Journal of SocioEconomics, 34, 656-673.

Locke, E. A. (1976). The nature and causes of job satisfaction. In M. D. Dunnette (Ed.), Handbook of industrial and organizational psychology (pp. 1297-1349). Chicago: Read McNally.

Locke, E. A., \& Latham, G. P. (1990). Work motivation and satisfaction: Light at the end of the tunnel. American Psychological Science, 1(4), 240-246. 
Long, C, S. \& Thean, L. Y. (2011). Relationship between leadership style, job satisfaction and employees' turnover intention: A literature review. Research Journal of Business Management, 5(3), 91-100.

Marston, S. H., \& Brunetti, G. J. (2009). Job satisfaction of experienced professors at a liberal arts college. Education, $130(2), 323-347$.

Morrison, T. (2002). How can values be taught in the university? Peer Review, 4(4), 4-7.

Perrakis, A. I., Galloway, F. J., Hayes, K. K., \& Robinson-Galdo, K. (2011). Presidential satisfaction in higher education: An empirical study of two- and four-year institutions. Journal of Higher Education Policy And Management, 33(1), 57-66.

Pettit, J. D., Goris, J. R., \& Vaught, B. C. (1997). An examination of organizational communication as a moderator of the relationship between job performance and job satisfaction. The Journal of Business Communication, 34(1), 81-89.

Pierce, D., Kaburakis, A., \& Fielding, L. (2008). Compliance officers' guide to navigating NCAA student-athlete reinstatement cases involving amateurism violations. Journal of Issues in Intercollegiate Athletics, 87-106.

Pincus, D. (1986). Communication satisfaction, job satisfaction, and job performance. Human Communication Research, 12, 395419.

Rubin, A. M. (1993). The effects of locus of control on communication motives, anxiety, and satisfaction. Communication Quarterly, 41, 162-171. 
Rubin, R. B, \& Rubin, A. M. (1992). Antecedents of interpersonal communication motivation. Communication Quarterly, 40, 305-317.

Ryan, T., Clopton, A. \& Irwin, R. (2008). Super support: A supportive supervisor, life satisfaction, and the mediating presence of coaching satisfaction. Journal of Applied Psychology, 3, 120 - 130.

Sias, P. M. (2005). Workplace relationship quality and employee information experiences. Communication Studies, 56(4), 375395.

Sojka, G. S. (1983). Evolution of the student athlete in America. Journal of Popular Culture, 16(4), 54-67.

Spector, P. E. (1985). Measurement of human service staff satisfaction: Development of the job satisfaction survey. American Journal of Community Psychology, 13(6), 693713.

Spector, P. E. (1997). Job satisfaction: Application, assessment, causes, and consequences. London: Sage.

Stier, J. F., Schneider, R. C., Kampf, S., \& Gaskins, B. P. (2010). Job satisfaction for campus recreation professionals within NIRSA institutions. Recreational Sports Journal, 34(2), 7894.

Wheatley, M. J. (2001). Leadership and the new science:

Discovering order in a chaotic world. San Francisco: BerrettKoehler.

Zhang, J. J., DeMichele, D. J., \& Connaughton, D. P. (2004). Job satisfaction among mid-level collegiate campus recreation program administrators. Journal of Sport Behavior, 27(2), 184-212. 
The Journal of SPORT, 2013, 2(2), 175-184

(C) Kent State University

\title{
Incentives on the Starting Grid in Formula One Racing
}

\author{
Laurence M. McCarthy \\ Seton Hall University \\ Kurt W. Rotthoff \\ Seton Hall University
}

\begin{abstract}
Starting a race in first place, pole position, is the goal of every race driver. This is even more pronounced in Formula One $(F 1)$ racing as the road courses they race are more difficult to pass on, providing an additional advantage to starting on the pole. However, their unique standing starts also create a bottleneck at the first turn, which often leads to contact between cars. Because F1 cars are not designed to make contact, this contact can greatly impact a driver's position on the track. We find that there are certain positions on the starting grid that are more likely to make contact with other drivers than other positions. Specifically the starting position with the highest odds to make contact at the first turn is position 10. This creates the incentive for drivers to avoid this position, which means if they are unable to qualify higher than this position, the incentive exists for drivers to intentionally adjust their behavior to avoid these high-risk (of making contact) positions.
\end{abstract}




\section{Introduction}

In Formula One (F1) car racing a defined procedure for the assignment of starting positions is used. Mandatory qualifying sessions lead to the fastest car/driver being awarded starting position one ("pole position") for the race. According to the procedure to reward top qualifying competitors with the best starting positions, it is assumed that performance outcome in F1 races would benefit (Muehlbauer, 2010).

Although qualifying first or in pole position is the goal for every driver, it is not clear that starting position in the rest of the field follows a linear relationship. Given that F1 races are a standing start, all cars are stopped and the race starts on a light, the cars that qualify further back in the field have a longer distance to the first corner which allows for more acceleration into the turn. This results in drivers further down the grid entering the first corner's breaking zone at a higher speed. This creates a 'Concertina Effect' going into the first corner. It is this effect that leads to contact between cars, and ultimately damage to the cars themselves. F1 cars are not able to be driven effectively, or able to perform as well, with damage; thus this early race contact significantly impacts the entire race for a driver.

Making it through the first corner unscathed is critical to success in a race. As such starting positions can be decisive. We analyze which starting positions are most likely to be involved in first corner accidents. Logically the pole-position holder will be ahead of any wreck, and those starting later in the field will have the chance to avoid the contact. Thus, if there is a certain group of starting positions that is more likely to be involved in a wreck, the optimal strategy of qualifying can be altered. It is possible that the better strategy is to intentionally move back in the starting grid in order to avoid the first turn contact. This information is valuable for both the F1 teams and the Federation Internationale de l' Automobile (FIA, the governing body of F1 racing).

Muehlabauer (2010) examines the relationship between the starting position and finishing position in $70 \mathrm{~F} 1$ races. He finds that the correlation between the starting position and finishing position is significant. He finds that there is a correlations coefficient of 0.63 ; 
we get similar result for the 2012 season used in our study. This is further confirmed in a working paper by Silva and Silva (2010), where they find that the qualifying performance of a driver is the best predictor of their finishing position in F1 racing. Allender (2008) focused on the National Association of Stock Car Racing (NASCAR), finding that a driver's years of experience plays a significant role in predicting the outcome of NASCAR races. These studies look at how the starting positions of these drivers impact their finishing positions. We take a step back; in order to finish the race you have to make it through the first turn (preferably without damaging your car), especially in F1 where first turn wrecks are common (Benson, 2012).

Optimal decisions in racing have been looked at by Bekker and Lotz (2009) and the tournament structure on between race incentives in NASCAR by von Allmen (2001) and Groothuis, Groothuis, and Rothoff (2011). We look at optimal qualifying positions by analyzing what positions on the starting grid are most likely to wreck on the first turn. To do this we get data from the 2012 F1 racing season and analyze the probability of wrecking on the starting position. The data suggests that a driver wants to avoid starting at, or near, the tenth position on the grid. Those cars starting tenth, and those cars starting closest to this position, are more likely to make contact in the first turn.

\section{Data and Methodology}

We analyze all 20 Formula One Grand Prix races organized by the (FIA) in 2012. We analyze data on the starting position, finishing position, and contact information, from major wrecks to minor contact, for each driver for each race during this season. ${ }^{1}$ The starting and finishing positions were matched to race reports on the first turn accident data. The data were gathered from: formula1.com, ESPNF1.com, bbc.co.uk/sport/0/formula1, grandprix.com, dailymail.co.uk/sport/formulaone, fl fanatic.co.uk,

\footnotetext{
${ }^{1}$ We attempted to gather data for 2010 and 2011, but no accurate data on contacts and wrecks in the first corner were found for those years. Thus the sample is restricted to 2012, where accurate data on first turn contact could be verified.
} 
motorsportpress.wordpress.com, telegraph.co.uk, racedepartment.com, paultan.org, edp24.co.uk, and vitalf1.com.

To measure the probability of a given driver, $i$, in a certain starting position making contact in the first turn, we use a probit estimation. To measure the probability of a given driver, $i$, in a certain starting position making contact in the first turn, we use a probit estimation.

$$
\text { Contact }_{i}=\beta_{1}(\text { Starting Position })_{i}+\varepsilon(1)
$$

The estimation, equation 1, allows us to analyze the odds that a driver makes contact in the first turn based on that drivers starting position. To control for any non-linearities in the data we also estimate equation 2 with a squared term.

$$
\text { Contact }_{i}=\beta_{1}(\text { Starting Position })_{i}+\beta_{2}(\text { Starting Position })_{i}^{2}+\varepsilon
$$

Equation 2's functional form allows for the relationship between the odds of making contact and starting position to not be linear. We expect this curve-linear specification to be more accurate given that there are two positions on the starting grid that have the ability to avoid contact in the first turn: the pole position and those starting last, because they have time to react to contact. These estimations are done for the full sample, only races that have some contact, and races that have major contact (more than four cars making contact). These different samples allow us to measure any difference across tracks that could be known for first turn contact.

In addition to the models specified above, we add a robustness check by creating a dummy variable for each starting position. The driver that starts on the pole is position $1, \mathrm{P} 1$, the second qualifier is $\mathrm{P} 2$, and so on. This estimation will reveal there is a relative difference in driver's probability of wrecking on the first turn, relative to the omitted variable: P1. Results for these three specifications are discussed in the next section. 


\section{Results}

The results for each estimation are done on each of the three samples: the full sample, the start of every race throughout the entire 2012 season, and two restricted samples. The first restricted sample looks at the odds of making contact only in races where contact is made in the first corner (which occurs in 14 of the 20 races). The second restricted sample analyzes the impact of races where major contact was made in the first corner. We define major contact as four or more cars making contact, which occurred in five of the 20 races.

Table 1 presents the results from equation 1 on how the starting position changes the odds of making contact in the first turn. For the full sample, column 1, the races where contact was made, column 2 , and the sample with major contact, column 3 , we find a negative and significant relationship. This shows that the further back a driver is in the grid, i.e. qualifying lower, decreases the odds of making contact in the first turn.

Table 1: Probit estimation on the odds of making contact based off the drivers starting position. Marginal effects reported for the full sample, limited sample to races with contact, and limited sample to races with a major contact.

\begin{tabular}{cccc}
\hline & $\begin{array}{c}\text { Full } \\
\text { Contact }\end{array}$ & $\begin{array}{c}\text { Restricted } \\
\text { Contact }\end{array}$ & $\begin{array}{c}\text { Restricted Major } \\
\text { Contact }\end{array}$ \\
\hline Starting Position & $-0.004794^{* *}$ & $-0.006874^{* *}$ & $-0.013988^{* *}$ \\
& $(0.002)$ & $(0.003)$ & $(0.006)$ \\
Observations & 477 & 334 & 118 \\
\hline Pseudo $R^{2}$ & 0.0158 & 0.0190 & 0.0414 \\
\hline \multirow{5}{*}{$\begin{array}{c}\text { Standard errors in parentheses } \\
{ }^{* * *} p<0.01,{ }^{* *} p<0.05,{ }^{*} p<0.1\end{array}$} \\
\end{tabular}

However, as we suggested earlier, we believe that there are two optimal positions: first (on the pole) and going last, because the driver has time to avoid contact. For this reason we analyze a curvelinear relationship between the staring position and odds of making contact in Table 2. 
Table 2: Probit estimation on the odds of making contact based off the drivers starting position. Marginal effects reported for the full sample, limited sample to races with contact, and limited sample to races with a major contact.

\begin{tabular}{cccc}
\hline & Full & Restricted & Restricted Major \\
& Contact & Contact & Contact \\
\hline Starting Position & $0.020212^{* *}$ & $0.028901^{* *}$ & 0.018988 \\
& $(0.009)$ & $(0.012)$ & $(0.024)$ \\
Starting Position $^{2}$ & $-0.001046^{* * *}$ & $-0.001493^{* * *}$ & -0.001378 \\
& $(0.000)$ & $(0.000)$ & $(0.001)$ \\
Observations & 477 & 334 & 118 \\
\hline Pseudo $R^{2}$ & 0.0433 & 0.0516 & 0.0561 \\
\hline \multirow{5}{*}{ Standard errors in parentheses } \\
& ${ }^{* * *} p<0.01,{ }^{* *} p<0.05,{ }^{*} p<0.1$ &
\end{tabular}

In Table 2 we find that the relationship between starting position and starting position squared is increasing at a decreasing rate. Thus, it is better to start either first or last, but not in the middle. This result holds true for all 3 samples, the full sample and the two restricted samples. However, the peak (the highest odds of making contact on the first turn) changes across the different samples, displayed in figure 1.

Figure 1: The estimated odds of making contact in the first turn, based on the starting position of the driver.

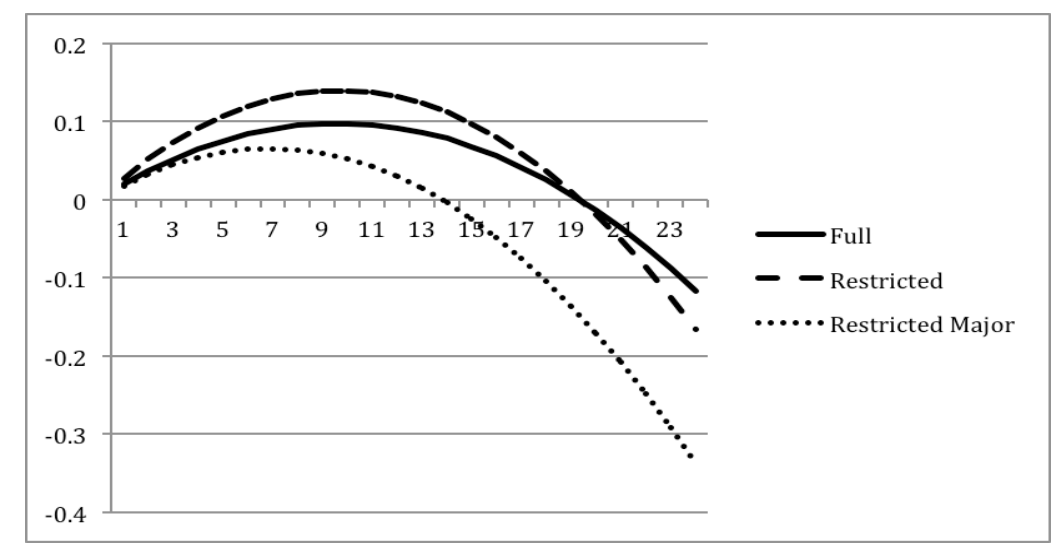


The peaks, which represent the highest odds of making contact in the first turn, exist at starting position 10 for both the full sample and the sample of races where contact is made. The full sample has lower odds of making contact, which is expected since it includes races without any contact. On the other hand, if a track is well known for contact in the first turn, then looking at the sample restricted to contact would reveal more realistic odds of the event occurring. As can be seen, those starting after the $20^{\text {th }}$ position have lower odds of making contact than the pole sitter.

When major contact is made, the peak occurs with P7. The curve also goes negative, again relative to $\mathrm{P} 1$, quicker; showing that when major contact is made it impacts the top 13 drivers the most.

\section{Robustness}

Table 3: Probit estimation on the odds of making contact based off the drivers starting position. Marginal effects reported for the full sample, limited sample to races with contact, and limited sample to races with a major contact.

\begin{tabular}{cccc}
\hline VARIABLES & $\begin{array}{c}\text { Full } \\
\text { contact }\end{array}$ & $\begin{array}{c}\text { Wreck } \\
\text { contact }\end{array}$ & $\begin{array}{c}\text { Major Wreck } \\
\text { Contact }\end{array}$ \\
\hline P2 & $0.948135^{* * *}$ & $0.921746^{* * *}$ & $0.851665^{* * *}$ \\
& $(0.012)$ & $(0.017)$ & $(0.039)$ \\
P3 & $0.948135^{* * *}$ & $0.921746^{* * *}$ & \\
& $(0.012)$ & $(0.017)$ & \\
P4 & $0.951087^{* * *}$ & $0.925535^{* * *}$ & $0.858156^{* * *}$ \\
& $(0.011)$ & $(0.016)$ & $(0.038)$ \\
P5 & $0.949899^{* * *}$ & $0.923883^{* * *}$ & $0.851665^{\star * *}$ \\
& $(0.011)$ & $(0.016)$ & $(0.039)$ \\
P6 & $0.951087^{* * *}$ & $0.925535^{* * *}$ & $0.858156^{* * *}$ \\
& $(0.011)$ & $(0.016)$ & $(0.038)$ \\
P7 & $0.951087^{* * *}$ & $0.925535^{* * *}$ & $0.865446^{* * *}$ \\
& $(0.011)$ & $(0.016)$ & $(0.036)$ \\
P8 & $0.944396^{* * *}$ & $0.918176^{* * *}$ & $0.843875^{* * *}$ \\
& $(0.009)$ & $(0.018)$ & $(0.040)$ \\
P9 & $0.951087^{* * *}$ & $0.925535^{* * *}$ & $0.851665^{* * *}$ \\
& $(0.011)$ & $(0.016)$ & $(0.039)$ \\
P10 & $0.949899^{* * *}$ & $0.923883^{* * *}$ & $0.851665^{* * *}$ \\
& $(0.011)$ & $(0.016)$ & $(0.039)$ \\
P11 & $0.951087^{* * *}$ & $0.925535^{* * *}$ & $0.843875^{* * *}$
\end{tabular}




\begin{tabular}{cccc}
\hline & & & \\
& $(0.011)$ & $(0.016)$ & $(0.040)$ \\
P12 & $0.949899^{* * *}$ & $0.923883^{* * *}$ & $0.843875^{* * *}$ \\
& $(0.011)$ & $(0.016)$ & $(0.040)$ \\
P13 & $0.951087^{* * *}$ & $0.925535^{* * *}$ & $0.851665^{* * *}$ \\
& $(0.011)$ & $(0.016)$ & $(0.039)$ \\
P14 & $0.952018^{* * *}$ & $0.926953^{* *}$ & $0.851665^{* * *}$ \\
& $(0.011)$ & $(0.016)$ & $(0.039)$ \\
P16 & $0.944396^{* * *}$ & $0.918176^{* * *}$ & $0.843875^{* * *}$ \\
& $(0.014)$ & $(0.018)$ & $(0.040)$ \\
P18 & $0.949899^{* * *}$ & $0.923883^{* * *}$ & $0.843875^{* * *}$ \\
& $(0.011)$ & $(0.016)$ & $(0.040)$ \\
P19 & $0.948135^{* * *}$ & $0.921746^{* * *}$ & \\
& $(0.012)$ & $(0.017)$ & \\
P20 & $0.944396^{* * *}$ & $0.918176^{* * *}$ & $0.843875^{* * *}$ \\
& $(0.014)$ & $(0.018)$ & $(0.040)$ \\
P22 & $0.944396^{* * *}$ & $0.918176^{* * *}$ & $0.843875^{* * *}$ \\
& $(0.014)$ & $(0.015)$ & $(0.036)$ \\
P24 & $0.942759^{* * *}$ & $0.916124^{* * *}$ & $0.831175^{* * *}$ \\
& $(0.013)$ & $(0.018)$ & $(0.042)$ \\
Observations & 398 & 279 & 89 \\
\hline Pseudo $R^{2}$ & 0.0643 & 0.0786 & 0.1352 \\
\hline & Standard errors in parentheses & \\
& $* * *$ & $p<0.01,{ }^{* *} \mathrm{p}<0.05,{ }^{*} \mathrm{p}<0.1$ & \\
& & &
\end{tabular}

As a robustness check we looked at each starting position's odds of making contact individually. In table 3 we run the probit regression and find that all positions are more likely to make contact than the omitted variable, $\mathrm{P} 1$. There are four starting positions that make no contact in our sample, P15, P17, P21, and P23, and thus they do not appear in table 3 . In all samples measured, we also find that the odds of making contact fall off for those drivers that qualify lower in the grid.

\section{IV.Conclusion}

Although the FIA would like every driver to be trying to qualify in the highest possible position during their qualifying runs, we reveal information that could impact a driver's optimal choice during this qualification process. There is often contact between 
drivers in the first corner of races and as such drivers have to decide if moving back on the starting grid, to decrease their odds of making contact with other drivers, is the optimal decision. The driver who starts $10^{\text {th }}$ on the grid has the highest odds of making contact with another car. The lowest odds of making contact occur for those drivers starting in the last five positions, or starting on the pole. For courses that are notorious for first turn wreckage, these odds should be taken into account for the driver (after they acknowledge they will not get the pole at that race).

A special thanks to Andrew J Moreno for his data work as our research assistant. Any mistakes are our own. 


\section{Works cited}

Allender, Mary (2008) Predicting The Outcome Of NASCAR Races: The Role Of Driver Experience Journal of Business and Economics Research Volume 6, Number 3

Bekker, J. and W. Lotz (2009) Planning Formula One Race Strategies using Discrete-Event Simulation Journal of the Operational Research Society 60, 952-961

Benson, A. (2012) Belgian Grand Prix crash: Romain Grosjean banned for one race. Retrieved 3/8/2013from http://www.bbc.co.uk/sport/0/formula1/19458954

Groothuis, Peter A., Jana D. Groothuis and Kurt W. Rothoff (2011) Time on Camera: An Additional Explanation of NASCAR Tournaments. Journal of Sport Economics Vol 12, No.5, 561-570.

Muehbauer, Thomas (2010) Relationship between Starting and Finishing Position in Formula One Car Races International Journal of Performance Analysis of Sport 10, 98-102

Silva, Kathleen M. and Francisco J. Silva (2012) A Tale of Two Motorsports: A Graphical-Statistical Analysis of How Practice, Qualifying, and Past Success Relate to Finish Position in NASCAR and Formula One Racing Working paper (access 3/1/13) Retrieved from http://newton.uor.edu/FacultyFolder/Silva/NASCARvF1.pdf

von Allmen, P. (2000) Is the Reward System in NASCAR Efficient? Journal of Sports Economics Vol. 2, No. 1, pp. 62-79. 
The Journal of SPORT, 2013, 2(2), 185-215

(C) Kent State University

\title{
The Historical Development and Marketing of Fantasy Sports Leagues
}

\author{
Rick Burton \\ Syracuse University \\ Kevin Hall \\ Syracuse University \\ Rodney Paul \\ Syracuse University
}

\begin{abstract}
By 2013, fantasy sports leagues (and games) were entered into and played by more than an estimated 32-million people (Dwyer, 2013) across American and Canada, and produced a projected economic impact of \$3.1-billion dollars annually (Fantasy Sports Trade Association, 2012). This work seeks to explain both the historical growth and cultural transitions of in-home sport gaming in the United States as well as the technological evolution that drove the appeal of modern 'fantasy sports' and continued enhancement of professional league avidity by developing stronger brand allegiances for leagues such as Major League Baseball (MLB) or the National Football League (NFL).

From a historical standpoint, the term 'Fantasy League' didn't garner popularity until the 1980s, but the concept of fantasy sports gaming can be traced back to the mid-1860s with a simple wooden tabletop contraption that simulated outcome elements of a baseball game (Cooper, 1995). Over the next 150 years, technological and social developments in the areas of in-home re-creation and networked gaming have caused fantasy sports to re-shape sports media coverage, sports marketing (particularly of sports data), fan avidity, technology engagement and general sport discussion.

The impact of these fan-based developments might prove significant and increasingly leagues like the NFL have been forced to ask whether the at-home experience of following professional football (including the owning and managing of fantasy football league teams) is reaching a point where it could replace attending NFL games in person. A sea-change such as that (decreases in NFL game attendance, failure to sell out NFL games, etc.) would potentially threaten lucrative team and league sponsorships, stadium merchandise and concessions (food, beverage, parking, etc.) and possibly even TV network broadcast contracts (by way of diminished ratings and advertising demand).
\end{abstract}




\section{Introduction}

While sport in its simplest form has captivated the interest of varied citizenry for many centuries (dating back at least until 776 B.C. with the creation of the ancient Olympics), the last 150 years has witnessed an increasing desire by fans to review, analyze, collect and manage professional athlete data (i.e., player performance metrics). Further, as technical access to game data and player statistics have become easier to aggregate and manipulate by individuals, media platforms such as magazines, newspapers, radio, television, internet websites and modern social networks, have generated increasingly deeper levels of consumer avidity, purchase and consumer control of the sport product. As demand for accurate statistical data has grown, the marketing of fantasy sport gaming has also evolved. Sports-related games have moved in a deliberate technological progression from simple wooden table games to "simulated team management" via cardboard games (Edelman, 2012) to computer simulation of imagined games to modern-day management of 'fantasy teams' (comprised of actual players) playing in 'fantasy leagues'.

In its contemporary form, fantasy sport can be defined as playing a game in which linked participants take on the roles of team "managers" or "general managers" and manipulate an aggregated "team" of players whose real-world performances generate point values that determine the outcome of head-to-head matchups. Play usually begins with a process known as a player draft wherein the consumer (acting as team owner) assembles a team made up of actual players from a professional league. This 'owner' then competes against other "owners" or "managers" in a fantasy league. Fantasy team owners earn points based on the real life statistics the players on their rosters generated in real league games. These points accumulate across multiple games creating a single game performance where the fantasy team owner wins or loses in head-tohead competition. Scoring systems vary across leagues, with players earning points for a variety of game statistics. For example, in fantasy football leagues, running backs and wide receivers may earn a point for every 10 yards gained carrying or receiving the ball and 6 points for each touchdown scored. 
In general, leagues consist of 8-12 teams and are comprised of groups of close friends or a grouping of relative strangers. Some leagues require entry fees with payouts to victors on a weekly and/or seasonal basis. Other fantasy leagues (including many popular online versions of fantasy sports) have no entry fee or cash prizes associated with participation. In either scenario, the ultimate goal of the fantasy owner is to win the fantasy league championship. In some leagues, owners compete head-to-head with another owner on a weekly basis, while other leagues highlight the entire season through a "rotisserie"-style framework where overall points or leading certain categories are key to overall fantasy owner victory. In prize leagues (monetary or otherwise), some are structured as winner-take-all, while others offer monetary prizes weekly or daily for individual team performance.

Whether there are monetary prizes or not, fantasy sports have led to key financial gains for websites who offer management of these leagues and thus attract key advertising dollars. Other websites charge monthly or annual fees (in addition to advertising revenue they generate) for their information about fantasy players and teams while television networks produce weekly or daily shows about fantasy sports. Finally, many of the professional leagues (such as the NFL) have embraced fantasy sports as part of their marketing plans.

As Strasser (1989, p. xi) noted, "Networks of human relationships are a fundamental aspect of culture" and these networks have been "essential to the development of what may literally be called consumer culture." Thus, stimulating replications of popular cultural events such as professional baseball or football games - be it through playing random-chance table toys, trading baseball cards distributed via tobacco brands or joining fantasy sports leagues - are logical constructions for individuals seeking to broaden their human networks. In writing on the historical evolution of brands, Strasser $(1989$, p. xi) posits that "consumer goods may be understood as artifacts of the new culture" and from this we can infer that sporting consumer goods (i.e., toys, board games, magazines or websites) are relevant cultural products that reflect the evolving interests of a particular age. 


\section{Historical Overview - The Tabletop and Board Game Era}

The roots of fantasy sports stretch to the mid- $19^{\text {th }}$ century and the earliest manufactured in-home games utilized a pinball-like design (Dulken, 2002). In Francis Sebring's 1866 Parlor Base-Ball game, a coin (representing a baseball) would be propelled along a flat wooden surface by a coiled spring (the pitcher) toward a movable flipper (the batter). The batter would then hit the coin into one of several open slots on the playing surface and create a specific outcome of the game-player's at-bat (Reilly, 2005). This format allowed the game player (the consumer) to imagine that the pitcher (the act of propelling the coin) and the batter was anyone known (locally or nationally) to the actual Parlor Base Ball player. Behaviorally, this gave the consumer a sense of controlling the product's usefulness and, in an era that featured increased amounts of leisure time, allowed for a pleasurable relationship with the product and the potential for great sentimental attachment (Strasser, 1989).

Further extensions of baseball's value as a vehicle for consumer attachment can be found in one of the earliest forms of American sports marketing in which mainstream tobacco brands such as "Old Judge, Goodwin Champions and Allen \& Ginter started issuing collectible baseball cards with cigarette packs in the late 1880s" (Burton, 2010a). These black and white cards or later color chromolithographs (Katz, 2009) were keen applications of a consumer product using the new sport and gaming "culture" to engage consumers and further drive brand investments. Since the first "publicly proclaimed professional baseball team had only been established" in 1869 with an "organized league of professional teams" following (McChesney, 1989, p. 52), it suggests the linkage between American sport and consumerism needed less than 20 years for incubation and evidence of professional player-endorsed in-home games (such as Zimmer's Base Ball Game or The Champion Game of Base Ball) and non-endorsed games (like Game of Base-Ball, National League Ball Game and Home Base Ball) would emerge by the dozens between 1869 and 1900 (Cooper, 1995).

In literature, evidence of the individual creating his own baseball team arguably first appears in Mark Twain's 1889 novel $A$ 
Connecticut Yankee in King Arthur's Court wherein Twain's protagonist Hank Morgan organizes a baseball game and places players drawn from King Arthur's peers and court in various fielding positions (Brock, 2010, Burton and Finkel, 2013 in press). Shortly thereafter, Charles Van Loan's 1912 short story, "The Phantom League" (from the book "The Ten-Thousand Dollar Arm") developed a narrative around a part-time baseball scout named Frisbee who is fooled into believing statistics drawn from the Independent Northern New Mexico Baseball League are real. Frisbee then determines he must travel to New Mexico to scout the players who are producing such notable statistics. In truth, as part of a practical joke, an individual named Meeghan is using "a mechanical ball-game device" to produce statistics for imaginary players that correspond to board-game tokens or counters.

Another hoax involving the fabrication of sports data and phantom players would actually make it onto the pages of the $\mathrm{New}$ York Times during the autumn of 1941 when an "imaginative" 35year-old Wall Street stockbroker named Morris Newburger began posing as the sports information director for a mythical institution named Plainfield Teacher's College. Each Saturday, Newburger, posing as sports information director Jerry Croyden, would phone in results from Plainfield's football games giving most of the credit for Plainfield's victory to a non-existent Chinese sophomore halfback named John Chung. Not long afterward, the New York Post columnist Herb Allan was writing in his "College Grapevine" column that "John Chung has accounted for 57 of the 98 points scored by his unbeaten and untied team in four starts. If the Jerseyans don't watch out, he may pop up in Chiang Kai-shek's offensive department one of these days." Hollander (1967) concludes her account of Newburger's charade by noting that "on Saturday afternoons they [Newburger and his associates] would take turns "calling the newspapers and manufacturing press releases about the marvelous feats" (p. 76) taking place at Plainfield. "For the stockbrokers this was certainly no money-making proposition. It was an investment in fun and fantasy. They wanted a winning football team and they got one" (p. 77). 
Twain and Van Loan's literary creations and Newberger's deceitful efforts suggest a period of growing consideration by sports fans to either extend the relevance of sport toys (i.e., the mechanical ball-game device used by Meeghan) or to manipulate actual sports coverage. In each case, there is evidence fans desired to manage game scenarios or outcomes personally. Facilitation for this concept began as early as the mid-1880's when British-born sportswriter Henry Chadwick developed the baseball box score for newspaper readers. This journalistic invention created "in capsule form who played, who won, who lost, who did well and who didn't" (Burton and Finkel, 2013 in press). A few years later in 1883 the first newspaper sports department was created at Joseph Pulitzer's New York World and in 1895 William Randolph Hearst introduced the first distinct sports section in the daily New York Journal. These actions by distinct newspaper brands showed that baseball statistics (i.e., wins, losses, batting averages, home runs), like industrial output, could be measured (McChesney, 1989).

Further, national media coverage of baseball players and even the anointing of players as favored brands (i.e., Mike 'King' Kelly) was leading to "the creation of popular songs such as "Slide, Kelly, Slide" (1883), which emerged as America's first "pop [musical] hit" in 1889 and Ernest Thayer's poem "Casey at the Bat" where actor DeWolf Hopper began performing as Mighty Casey on vaudeville stages in 1889" (Burton, 2010). This meant sport was now covered in great detail by the mainstream media and that players were emerging like breakfast cereal, biscuit and chewing gum brands: as products that, either at the stadium or as re-creations, were affordable for mass audiences and capable of satisfying mass engagement desires (Strasser, 1989).

Ultimately, we can infer that if board games, songs, vaudeville recitations, popular novels or baseball-specific narratives were married with baseball box scores and daily sports coverage of human performance, simple physical simulation games such as Parlor Base-Ball or Major League Indoor Base Ball would lead baseball fans into further manipulating fantasy game simulations by incorporating existing statistics or by creating new statistics of their 
own from the use of randomization devices such as dice, spinners, or cards (Cooper, 1995; Cochran, 2005).

One such invention that would emerge was "National Pastime", a tabletop baseball game designed by Clifford Van Beek and published by Major Games in 1930. Here, using dice and individualized cards, Van Beek's National Pastime was the first game to attempt to accurately simulate the performance of actual major league baseball players (Albert and Bennett, 2001). In contrast, players represented in prior mechanical games all had the exact same chance of all potential batter outcomes (singles, home runs, strike outs, etc.) as every other name in the game player's imagined line-up (Reilly, 2005). National Pastime used real player statistics (or a statistically-directed approach), so Yankees great Babe Ruth would hit more home runs, draw more walks and strike out more than other represented players (Bowman and Zoss, 1989).

The demand for more player-specific outcomes in sports simulation games changed this industry in the years following the introduction of "National Pastime". In 1941, former big league baseball player Ethan Allen sold the Cadaco-Ellis board game company a new game called “All Star Baseball” (McNeil, 2008). Like National Pastime, it used actual player statistics to provide enhanced fantasy game-play. Circular cards represented real-world players and each card was divided into 14 numbered segments (in a pie-chart style). Individual segments represented a possible outcome for the player's at-bat such as Home Run, Walk, Strikeout or Groundout. The size of each outcome segment corresponded with the player's actual statistics (Brock, 2006). Again, the Ruth circular featured a larger home run segment than other big leaguers. When a player was up to bat, their card was placed under a metal spinner. Wherever the spinner landed would create the result of that specific at bat.

APBA Baseball, another baseball game, closely inspired by National Pastime and All Star Baseball, would be introduced to the gaming market by Richard Seitz in 1951 (APBA Games, 2011). It was followed in 1961 by Strat-O-Matic Baseball, which was invented by Bucknell University mathematics major Hal Richman who had begun "to develop the game as an 11-year-old in 1948 after 
becoming dissatisfied with the statistical randomness present in other baseball games of the era" (Edelman, 2012). Richman's game included one playing card for each MLB player with each card providing ratings and results tables that corresponded with dice play (Miller, 2011; Edelman, 2012). Ultimately, Richman "survived money-losing years, royalty demands from [baseball's] players union and challenges from well-heeled competitors as his invention became the leading baseball board game." After inventing games for the NBA, NFL and NHL, he added "advanced versions for baseball that featured ratings for hit-and-run ability, outfielders' throwing arms and pitchers' endurance" (Miller, 2011).

In between Seitz's work in 1951 and Richman's distribution of Strat-O-Matic Baseball in 1961, Harvard professor Bill Gamson, developed The National Baseball Seminar in 1960 and became the first to invent a multi-player fantasy game prototype in which the players, acting as team owners, worked from remote or satellite locations (Allis, 2006). Gamson's concept involved aggregating 25 league members who worked with a "mythical \$100,000 at spring auctions to acquire real players and manage a team in each [of baseball's two] major leagues." When Gamson moved to the University of Michigan in 1962, he brought Seminar (named so the Cambridge, Mass., post office would not think he was "running a bookie operation") with him and he ultimately influenced two individuals, Robert Sklar and Daniel Okrent, who would completely re-shape fantasy sport development through a variety of viral tactics (Allis, 2006).

But Gamson was not alone in stretching the boundaries of fantasy sport development since nearly simultaneously in December 1960, John Burgeson, "a mid-level programmer at IBM in Akron, Ohio invented a form of computerized fantasy baseball" that "presaged the rudimentary concepts of sabermetrics" (Kalb, 2012). By Burgeson's own editing on Wikipedia in January 2009, the retired computer programmer claimed that "an early form of fantasy baseball was coded for an IBM 1620 computer in 1960 by John Burgeson, IBM Akron." According to Kalb (2012), Burgeson's creation was "essentially a digital version of Strat-O-Matic" played on an extremely expensive machine and was decidedly anti-social. 
What it did, though, was allow the computer to "generate outcomes based on the relative strengths and weaknesses of those players' preexisting stats." The significance of this development (or invention) was Burgeson's determination that "quantitative multivariable computer analysis could determine the relative merits of baseball players and figure out who would win a game."

Interestingly, it was a "marbles and nails" primitive pinball board game called Put-N-Take Baseball which was made by Northwestern Products of St. Louis and patented in 1933 that had first inspired John Burgeson to create an imaginary baseball league with his brother Paul in 1948. By 1960, he was able to merge the IBM 1620's "algorithmic alacrity" and turn it into a "little baseball simulator" (Kalb, 2012).

From a marketing standpoint, we can suggest these dedicated (or perhaps extreme) baseball fans, many working in isolation, were mixing simulation concepts with play-at-home toys or game brands like National Pastime, Put-N-Take Baseball, APBA, Strat-O-Matic Baseball and All Star Baseball in order to create more fully evolved fantasy game forms. This growing interest in managing self-created teams and leagues mixed with evolving technology and brand sophistication (Christ and Anderson, 2011) would ultimately lead to the group-engaged gaming concept we now call "fantasy sports".

Kotler (1991) has suggested that a brand is widely defined as a "name, term, sign, symbol, or design or combination of them which is intended to identify the goods or services of one seller or group of sellers and to differentiate them from those of competitors" Building on this, Aaker $(1991,1996)$ has often discussed the concept of strong brands or brand development via segmented industries and product line extensions. Thus, while marketing of toys or games was initially (and primarily) focused on children (and, in particular, boys) during the early to mid- $20^{\text {th }}$ century, emerging statistical access benefitting older baseball fans would sow the seeds for new baseball by-products and loosely-linked networks that started incorporating real-time data and game outcomes. Thus, despite narrow demographic targeting by early toy and board game manufacturers, "fantasy" game-play using actual player statistics started to come of age for an older male demographic during the 1960s and 70s. What 
had been missing up to this point was the ability of "participants to showcase managerial prowess [when] predicting future events" (Huey, 2005; Edelman, 2012).

\section{The Prognosticators, Rotisserie League and Expanded Data Era}

By the early 1960 's, the earliest documentation of what can be considered a future-outcome focused fantasy sport league was starting to emerge. It gained speed in 1963 when Bill "Wink" Winkenbach, a front office employee of the Oakland Raiders organized the "Greater Oakland Professional Pigskin Prognosticators League", or GOPPPL (Essler, 1994). To join the league, individuals were required to meet the following criteria: Administrative affiliation with an AFL franchise, professional journalistic relationship to professional football or to have purchased or sold ten Oakland Raiders season tickets (Schauf, 2010). Winkenbach had been running similar golf and baseball games among his friends since the mid 50's, but GOPPPL is now considered one of the first examples of a fantasy league (Harris, 2003).

Although the fantasy sports concept had only percolated during the 1960s, wider exposure of multi-player gaming would not arrive until 1979. That's when sportswriter Daniel Okrent, a figure many sport historians now consider the "father of fantasy sports", introduced a product he called Rotisserie Baseball (Wulf, 1984). While working as a writer for the now- defunct sports magazine Inside Sports, Okrent drew on his 1965 exposure to Gamson's The National Baseball Seminar (TNBS) from Robert Sklar, his freshman advisor at Michigan. Sklar had participated in TNBS with his Harvard and University of Michigan professor Bill Gamson during the early 60's (Allis, 2006; Edelman 2012) and introduced Okrent to Gamson's concept. From there, Okrent devised the idea of Rotisserie baseball (named after a restaurant, La Rotisserie Francaise, frequented by Okrent) during a flight to Austin, Texas (Walker, 2006). Rather than accruing points directly from individual players as discussed earlier, his scoring system was based on winning individual statistical categories to accrue points; each category won accounts for 1 point. For example, if the players on Team A 
combined to hit 7 home runs and the players on Team B hit 10 home runs, Team B earned the point for the Home run category. Teams would face off head-to-head for a week at a time hoping to win more points and the overall matchup. Players were drafted in an auction style. Managers were given a certain amount of theoretical money to start with and would bid on each player (Eisenberg and Waggoner, 1984). After the first season of Okrent's Rotisserie League, he published an article in Inside Sports entitled "The Year George Foster Wasn't Worth \$36”. The story introduced Okrent's fantasy league to a mass market and triggered the creation of similar leagues across the country (Schwarz, 2004).

At this point, public interest in more complete and alternative sports statistics was rapidly increasing. Before 1977, most baseball statistics available to the public came through newspaper box scores or periodicals such as the Sporting News which provided weekly box scores and team summaries for its baseball readers. However, in 1977, Bill James provided the start of a baseball statistical revolution when he published his Baseball Abstract. This annual book focused on detailed baseball statistics beyond what was traditionally available in newspapers or distributed verbally during baseball or radio broadcasts. James' self-published books developed a strong following (mainly through small advertisements placed in the Sporting News) and, in 1982, his operation was purchased by a media conglomerate and distributed to a much wider audience. His analysis spawned the SABR (Society for American Baseball Research, soon known as Sabermetrics) and the overthrow of traditional baseball statistics. It also led to widespread proliferation of books, magazines, and websites devoted to more detailed analysis of baseball data. Groups such as STATS, Inc. were formed in order to provide content to sports leagues for broader baseball fan consumption. Today, staples of the baseball statistics industry such as Baseball Prospectus, The Hardball Times, and web-darling Fangraphs all owe debts of gratitude to James and his belief baseball stats could be marketed widely and profitably distributed.

The intense interest in baseball statistics which arose during this timeframe not only enhanced the fantasy sports data revolution of the 1970's and '80's but ultimately led to millions of newly- 
designed line extensions generated from Winkenbach, Gamson, and Okrent's initial fantasy sports brands. As Christ and Anderson (2011) note, what was changing during the 1950-80's was a "strengthened consumer service and satisfaction [driven] by reducing service response time and increasing communication between salespeople and customers." In short, baseball and media brands profiting from baseball's cultural relevance were moving into an age when technologically-efficient service providers could extend MLB's new product forms. Simulated baseball games, once played in isolation, were now played by a broader spectrum of consumers and the possibility of 'owning' a team of real-life players was sufficient incentive.

\section{The Technology Era}

Coupling an expansion of fan interest with data and everquickening availability of sports statistics to a mass market from technological breakthroughs such as the World Wide Web and electronic mail led to a massive expansion of fantasy gaming. Historically speaking, the "birth" of the internet is often stated as being 1969 and it was followed with the establishment of email in 1977. But the broad commercialization of this platform did not begin until the late 1980s when greater strides in internet usability and access came about with the introduction of the World Wide Web (WWW) in 1991. This was further enhanced by Microsoft when the Seattle software and systems company rapidly inter-connected the computer marketplace in 1996.

Understandably, the use of technology in fantasy sports endured humble beginnings and Lee Eisenberg, another writer and original Rotisserie league player with Okrent, recalls marveling at his fantasy baseball statistics once being faxed to his office. At the time, this was the fastest technology for sharing statistics with a large group spread over a large geography. But the leaps to come in technology transfer would soon make faxes look like Egyptian hieroglyphics. In 1989, fantasy technology took a major step forward with Dugout Derby, a telephone based service created by Phoneworks in association with advertising agency Wakeman \& Deforest. For a minute-based fee ( $\$ 2$ for the first minute; $\$ 1.50$ for 
each subsequent minute) Dugout Derby allowed individuals to compete in rotisserie baseball over the telephone. Customers would play by placing a call, entering a credit card number, and other personal information. To perform team transactions (add, drop or trade players), the caller needed to input a special access code which was printed in 12 of the United States' major daily newspaper markets. This code changed each day in an attempt to increase newspaper subscriptions. With weekly and end of season prizes including trips, merchandise and cash, Dugout Derby attracted hundreds of thousands of managers.

During 1990, Dugout Derby received more than \$8-million worth of calls and appeared to a circulation base of 7.5-million people. Upon the introduction of Dugout Derby, the Philadelphia Inquirer expected to sign up 5,000-7,000 managers, but drew 15,058 during the first three weeks alone. Across the country, it became apparent baseball fans were quickly becoming Dugout Derby managers. Demographic data of these managers (similar to modern day fantasy players) was: $78 \%$ male, $25-49$ years old, had earned a college degree, owned their own home and regularly read the newspaper. Thanks to Dugout Derby's success, Phoneworks went on to offer similar games for the NFL (Pigskin Playoff), PGA (Fairway Fantasy), and NASCAR (Pedal to the Metal). Each line extension had incredible success in garnering callers and signing major sponsors such as Spalding and Gillette (Wojitas, 1991). Mass scale interconnection was setting the stage for the explosion of internet based fantasy sports.

The initial appeal for these fantasy sports was the internet's growing availability and immediate digital aggregation of player statistics. It made tracking league performance considerably easier (vs. relying on the next day's newspaper box scores). However, even with the availability of these statistics, managers were still forced to tabulate fantasy scoring and results manually. Rather than having the league commissioner compile these calculations in addition to facilitating transactions throughout the season, a branded internet league management system became the logical next step. In 1995, ESPN became the first major entity to offer an online version of fantasy sports on their website, ESPN SportsZone (Xiong, 1997). 
Less than two years later, on January 1, 1997, Peter Pezaris launched Commissioner.com. For $\$ 300$ per league, his company offered to eliminate the tedious work involved in managing a fantasy season. Commissioner.com was an early winner in the newly created fantasy league "hosting" market and was followed that same year by CBS Sports offering their own fantasy service beginning in 1997 (Ibid). The next year, CBS Sports officially partnered with Commissioner.com to offer fantasy games and, by 2001, purchased it outright for \$31-million. In just a few years Commissioner.com had established itself as the standard for an online fantasy sports service and warranted the attention (first) and then acquisition by a major sports network (Adams, 2003).

Just as Commissioner.com created the standard for fantasy league management, RotoNews.com set the standard for the way fantasy sports news would be disseminated. Rather than writing complete articles, RotoNews provided "player notes". Whenever a player was hurt, benched, released, signed or traded, an update was made to their respective player page. Fantasy managers could now find the latest information about players on their teams, and make informed decisions more easily (Berry, 2010). RotoNews, and its later iteration Rotowire, enjoyed numerous firsts in the fantasy industry including the internet's first free-to-use fantasy league management service (1998) and the 2004 provision of player updates to mobile phones (Rotowire, 2011). During these early years, the overall business model for fantasy league hosting services was largely pay-to-play. Companies like Commissioner, ESPN, and CBS Sports garnered all their revenue directly from the users. However, this approach would evolve and in 1999 Yahoo! became the first major entity to offer a league hosting service free of charge (Yahoo!, 1999). A strategy of relying on website advertising dollars helped Yahoo! become the most visited fantasy sports offering on the internet with FSTA President Jeff Thomas contending that by offering a free service Yahoo! became the fantasy market leader (LaMonica, 2006). 


\section{Technological Marketing}

Up until the introduction of the internet to a mass audience, fantasy statistics were tracked with newspaper box-scores leading to hand-filled-in ledger sheets. Following widespread adoption of the internet, however, scoring was tabulated digitally. This growing ease of coordinating league management, tallying results accurately and presentation of league "standings" has led to estimates suggesting more than 32-million Americans are playing in fantasy leagues and generating approximately $\$ 4$-billion of economic impact (FSTA, 2011). Understanding this rapid expansion is aided by acknowledging by data and website access through cellular and mobile phones starting in the early 2000s. It was followed by faster broadband speed (marketed heavily by numerous service providers), Wi-Fi access in public settings (promoted by retailers) and the introduction of applications (known as apps) designed for revolutionary technology brands such as Apple's iPhone and iPad. Developers of fantasy sites were quick to recognize the need for banter between users and started creating numerous features to accommodate networked dialogue. Yahoo initiated a 'smack talk' section directly into their scoreboards for each head-to-head fantasy sport they offered and some services took things even further. Bloomberg Sports hired New York Mets Hall of Famer Keith Hernandez in 2010 to record about forty videos of Hernandez talking trash about typical fantasy baseball happenings (Bloomberg Fantasy Sports, 2010). With Hernandez making wise-cracks about everything from bad trades or poor lineup decisions, to bragging about "owning" players like Phillies All-Star Chase Utley, users of Bloomberg fantasy baseball could send 'trash talk' videos to other league members, taking product engagement to the next level.

This fit a 2007 study by Farquhar and Meeds that separated fantasy sports users into five groups based on their motivations for playing. In order of size from largest to smallest the users represented were: "Casual players", who primarily participated for entertainment value, devoted less than 2 hours per week and spent less than \$20 annually on fantasy sports. "Skilled players", enjoyed the surveillance aspect of "information gathering, working with 
statistics, and staying in touch with real-world sports." They believed fantasy success stemmed from skill rather than luck.

"Isolationist thrill-seekers" were most motivated by escape from everyday life, lack of social interaction, and a need for arousal.

"Trash Talkers" had similar profile of the previous group, however with more of a need for social interaction. "Formatives" are those who do not appear to show a major motivation yet, likely due to inexperience in playing fantasy sports, and their youth (average age 20.5). Taking a simpler look at the data, the study separated the sample in to two groups. Those who were highly involved enjoyed the statistics and skill-based aspects, whereas participants with low involvement sought the thrill of victory and bragging rights (Farquhar and Meeds, 2007).

Looking at the consumption habits of fantasy managers, demographic and psychographic research shows the average participant is: male $(80 \%)$, Caucasian $(91 \%)$, holds a bachelor's degree or higher $(70 \%)$, has more than five years of internet experience (84\%), earns between $\$ 60,000-\$ 100,000(\$ 94,000$ is the average), and spends roughly $\$ 200$ annually on fantasy sports entry fees, player purchases and data reviews. Fantasy players were also stronger consumers in major product categories such as beer/alcohol, fast food, airline travel, video games, sports periodicals, athletic shoes, cell phones and credit card usage when compared to the general population (IPSOS Public Affairs, 2008). Additionally, more than $40 \%$ of these participants operated in a two-screen environment - Laptop and TV - on Sundays (World Fantasy Games, 2011). Drayer et al (2010) found that fantasy participants are likely to utilize the Internet, television, cellular telephones, and a variety of print media, (all on a locally and nationally covered scale) at much higher levels as a result of their interest and participation in fantasy football. Naturally, viewership of NFL games also increased as a result and for many users reached highest-ever levels. Interestingly, some users also reported seeking out more information on NFL player's personal lives and community involvements in response to owning them in a fantasy league (Drayer et al, 2010).

For sports leagues, this enhanced avidity and content consumption has proven beneficial. Early in the continuum of 
fantasy sports, the perception by professional leagues of fantasy participants might have held that only children or a narrow niche of statistical 'geeks' were engaged with this form of gaming. To wit, that would not have been an attractive demographic to target (at least for most traditionally-marketed consumer goods). However, research from 2011 shows fantasy sport participants wield significant spending power and has emerged as a dynamic demographic given the presence of social networks linking "league" members and the constant interaction (word-of-mouth) by these fantasy sports gamers online and offline.

Gender is also becoming a more closely examined topic in the fantasy sports world. Sport in general has long been considered the domain of men and, to little surprise, fantasy sport engagement appeared to follow the same path at first. Recently, however, there are indications of more female involvement. Male participation, the IPSOS study found, dominates but specific services report a growing percentage of category diversification via females. David Geller, director of fantasy sports at Yahoo!, said 14\% of the fantasy site's users were women, and they "have seen an upward trend". For ESPN, about $18 \%$ of its fantasy content was consumed by women, with growth in the low double digit percentages (Berr, 2009). Internet sites like Girlsfantasyfootball.com, once used the motto "For Women, By Women", to get more women involved and debunk myths regarding the difficulty of playing fantasy football. "Fantasy Football is easy and a lot of fun. You don't need to know anything about football to play fantasy football, really! It is easy to learn and easy to play. And contrary to popular belief, it doesn't take a lot of time. If you have fifteen minutes a week, you have time for Fantasy Football. The camaraderie and competition between friends, family and spouses adds to all the fun. Take the leap; you won't regret it" (GirlsFantasyFootball.com, 2011).

\section{Advertising/Sponsorship/Economics}

Fantasy football revenues including advertising ventures, sponsorship agreements and special events ultimately led to the creation of the Fantasy Sports Trade Association (FSTA) and it was 
formed precisely because of this segment's notable growth. The FSTA mission included providing "a forum for interaction between hundreds of existing and emerging companies in a unique and growing fantasy sports industry" and to "serve the small, the large, the entrepreneurs, and the corporations [as well as] the pioneers that invested in and grew the industry in the 1980's and 1990's." FSTA also claims to serve the "visionaries, innovators, investors, advertisers, and sponsors that would like to network and learn more about the exciting fantasy sports" (FSTA, 2011). With more than 100 member organizations, FSTA has secured many influential sports representatives from CBS Sports, Advance Sports Media, USA Today, STATS Inc and Rotowire. Through trade conventions, newsletters, market research, and media relations, FSTA is helping grow the fantasy sports industry and the most important aspect might be reflected in fantasy sports advertising. Between September 2010 and January 2011, Yahoo's mobile fantasy app/website saw 1.3billion ad impressions from official sponsors like Toyota and Subway. Yahoo sought to increase engagement with users, giving them more interactivity and features (Tsirulnik, 2011). Seeing online "eye-popping growth", Yahoo! knew advertisers were "shifting from mass-reach vehicles to depth-of-engagement vehicles" (Holahan, 2006).

Sponsoring fantasy games has also proven to improve awareness of a company and in 2009, The Sporting News ' main fantasy football sponsor, Castrol, saw improvement against competing motor-oil brands. This sponsorship was highly involved as The Sporting News' site was skinned with Castrol logos and its colors. Plus, TSN cleverly branded 'buttons' and site features (Eckardt, 2009). By increasing depth of engagement, Castrol's page views skyrocketed in September 2009, surprassing brand leader, Shell. The increase was largely attributed to $T S N$, as it was responsible for $12 \%$ of referrals to Castrol's site, a higher percentage than even Google searches (Merrihew, 2009). In baseball, a 2009 sponsorship success emerged when Burger King became the official sponsor of Major League Baseball's "Beat the Streak" fantasy game. The game called for users to select one player each day, trying to string together the longest streak of days with hits. If the customer's 
player went hitless, their streak went back to zero. Research after the 2009 season by Turnkey Sports \& Entertainment showed Burger

King surged to the top of consumer awareness among quick-service restaurants, ahead of Taco Bell, the official fast food sponsor of MLB (Broughton, 2009). Further, as Sports Business Daily reported, "The more prominent new advertising trend in fantasy sports is the custombuilt fantasy contest for a corporate sponsor or a game in which the sponsor itself becomes part of the content" (Fisher, 2010). Its report specifically mentioned RotoHog's development of fantasy games for GoDaddy.com, LG and Fathead; Fantasy Sports Ventures' 2009 deal with Sprint and Citizen Sports Network's project with Miller Lite for the NCAA basketball tournament.

While it has many positive aspects, fantasy related marketing or advertising can also lead to controversy. One instance occurred when the NFL used the injury of a player as the basis for an advertisement of their online fantasy football offering. The ad depicted Kansas City Chiefs running back, Jamaal Charles, shortly after he sustained a season ending ACL injury. In bold type, the ad copy read "Injury ruined your fantasy season? Start again on NFL.com." The advertisement was used to promote online fantasy leagues which begin mid-season, giving players who performed poorly in other leagues the chance to start with a clean slate (Boren, 2011). Because the NFL was theoretically profiting from an injury to one of its players, the ethics of the ad were called into question and the commercial caused a stir online where many called the ad dehumanizing. The NFL quickly issued an apology, calling the ad a 'mistake' (Nudd, 2011). A similar advertisement ran in 2010 for Sprint Wireless with a doctor attending to a fictitious pro football player with a serious knee injury. The player was shown asking what the injury would mean for him, to which the doctor responded "it means I'm dropping you from my fantasy team" (Hounsell and Galvez, 2010). This advertisement was also thought to dehumanize the player, but because it was fictitious there was not a significant response. 


\section{Conclusion}

Sports fans have historically shown a desire to get closer to their favorite sports and because of their avidity sport-themed toys or fantasy games have been developed to capitalize on this fascination. As Christ and Anderson (2006) noted, evidence suggests adopting the latest technology is a long, ongoing process that can be traced back at least to the beginning of professional personal selling in the mid-1800s. This engagement has correspondingly evolved with both the development of economic concepts such as disposable income and 'spare time' but also the creation of professional sport leagues and the invention of new game forms (such as basketball by Dr. James Naismith in 1891). The development of in-home baseball games arguably led to computer simulations where statistics were manipulated for social gaming. When those engagements were married with the internet and social networking such as Twitter, professional sport would benefit from the creation of fantasy leagues. Further, as data accessibility became more efficient to procure, it strengthened professional athlete awareness, monetization protocols and social connectivity by fans. Not surprisingly, with each technological development, fantasy gaming has grown more interactive and received increasing levels of media coverage (dedicated to fantasy gamers).

Before fantasy sports entered the mainstream, typical sports fans were likely familiar with specific teams, league superstars and perhaps a rival team's top players. Only obsessive or diehard fans of a sport were likely to learn about all the players in an entire league. These avid consumers felt a stronger connection to their favorite sport and possibly even a sense of personal investment in the sport product (rather than just acting as a passive observer). This investment has required more information about lesser known players which in turn has led to fans creating fantasy teams and joining networked leagues. Easier data acquisition has amplified attention to player statistics and contemporary technology which, in turn, has led sport practitioners to develop new revenue sources via the operation of fantasy websites, creation of on-line advertising, fantasy-related television and radio 
shows, sales of magazines and on-line subscriptions related to fantasy player evaluation.

While this work provides a contemporary history of fantasy sports, future researchers may wish to explore how fantasy sports games (or leagues) evolve and influence actual in-stadium game attendance or commitment to a single team. In particular, the changing needs of individuals to control their sporting heroes (increasingly accomplished via video games) should be of significant interest to media outlets, sports leagues, teams, individual players (and their agents) and sponsors because home team loyalties (and investments in that team) may become secondary to fielding an elite fantasy team and winning a fantasy league. Additionally, while the NFL is currently the dominant league in terms of fantasy sport popularity, this was not always the case, as baseball table games and fantasy Rotisserie-style leagues once dominated football in gaming popularity. Such shifts in cultural relevance and the transitions of what Strasser (1989, p. xi) called the "networks of human relationships as a fundamental aspect of culture" warrant a greater investigation for researchers, historians and brand marketers.

The authors wish to thank Syracuse University students Noel Byrd and Erica Belanger for their academic and technical support on this project. 


\section{Historical Development and Consumerism}

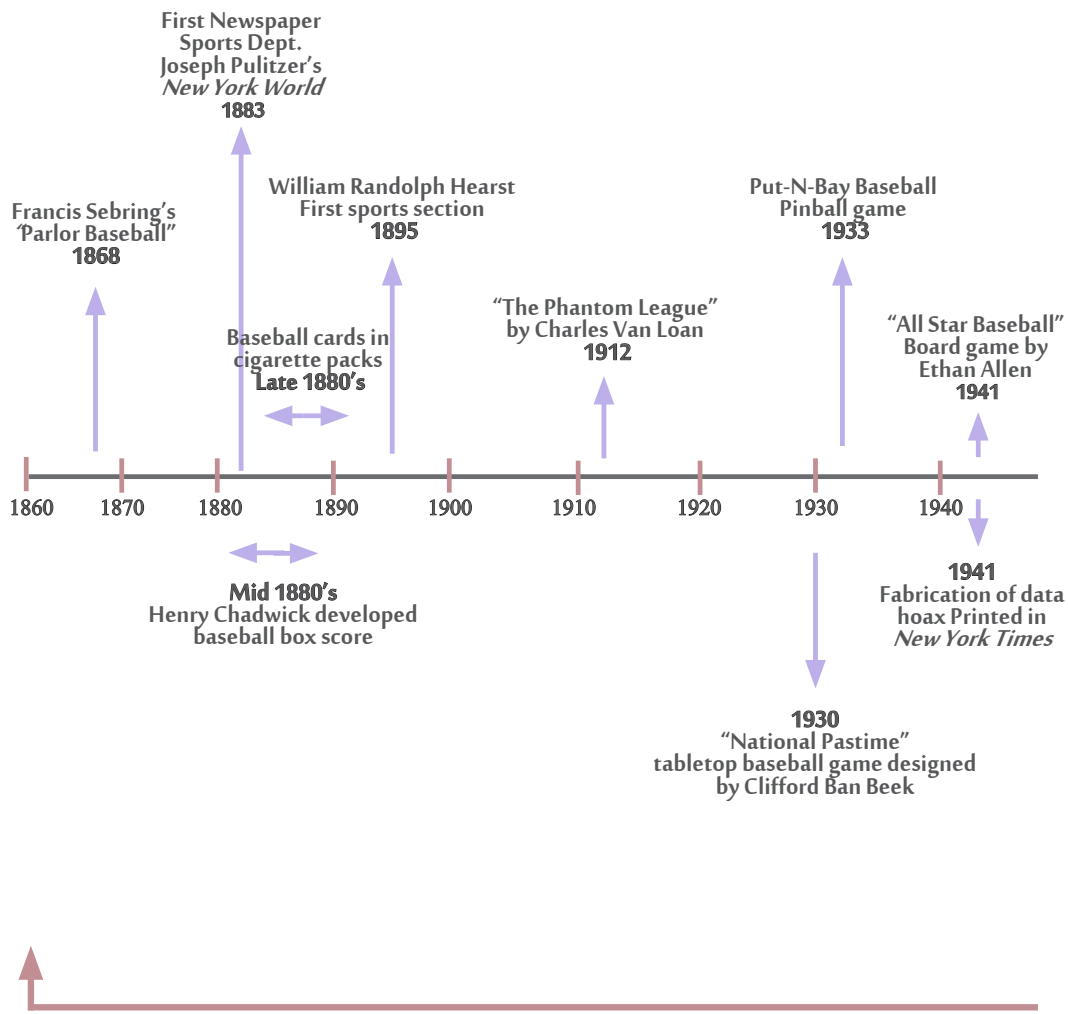

The Tabletop and Board Game Era 


\section{of Fantasy Sports Games and Leagues}

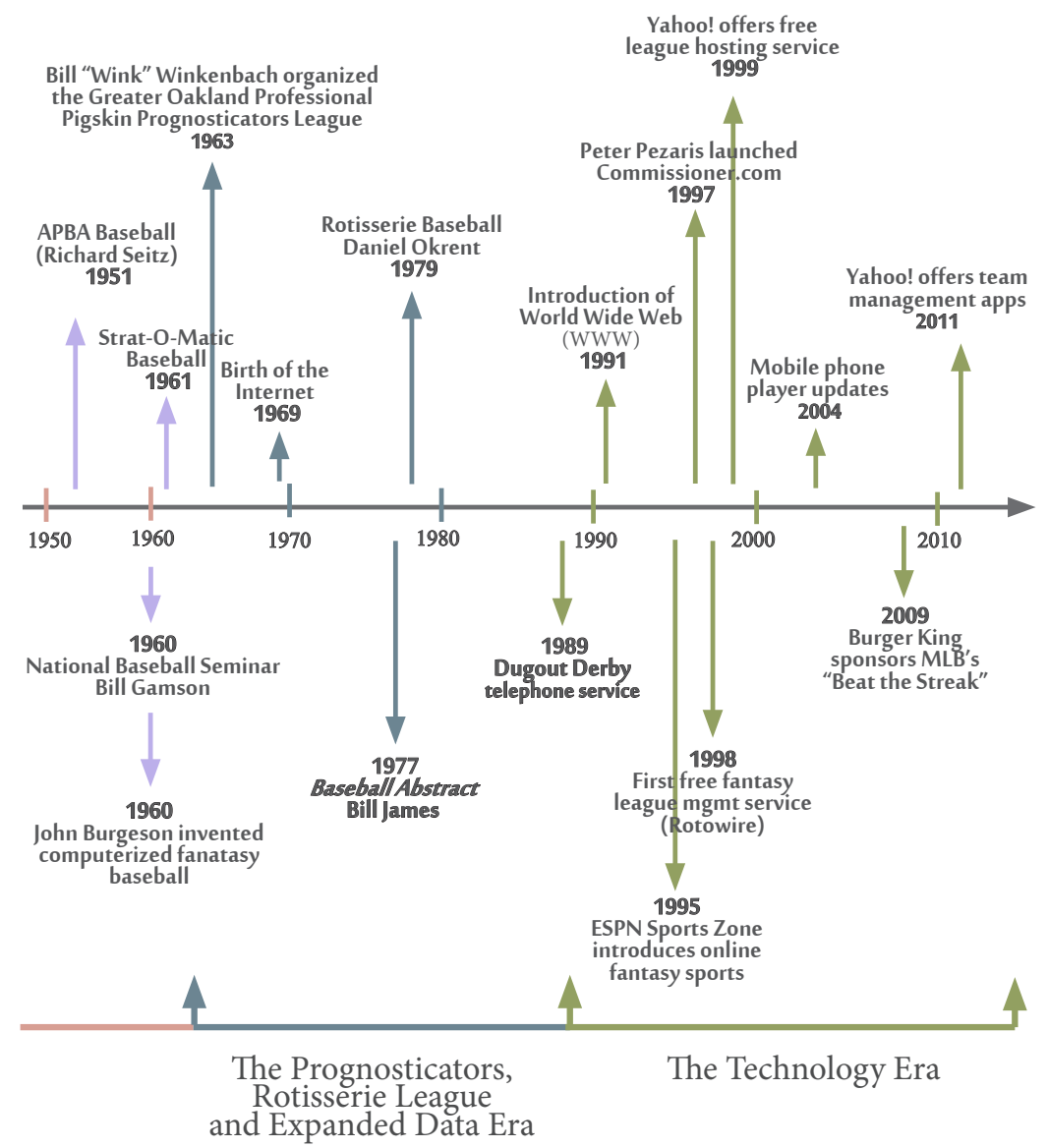




\section{References}

Aaker, D. (1991), Managing Brand Equity: Capitalizing on the Value of a Brand Name, The Free Press, New York.

Aaker, D. (1996), Building Strong Brands, The Free Press, New York.

Adams, R. (2003) "Peter Pezaris", Sports Business Daily, available at:

http://www.sportsbusinessdaily.com/Journal/Issues/2003/11/ 20031110/Forty-Under-40/Peter-Pezaris.aspx (accessed 5 November 2011).

Albert, J. and Bennett, J. (2001), Curve Ball: Baseball, Statistics, and the Role of Chance in the New Game, Copernicus/Springer-Verlag, New York, NY.

Allis, S. (2006), "Lords of the Games; Fantasy Baseball Indebted to Two Innovators", Boston Globe, March 12, A3.

APBA Games, "Company History", available at: http://www.apbagames.com/stadium/about_us/index.html.

Berr, J. (2009), "Media World: Ranks of women fantasy football players growing" DailyFinance.com, available at: . http://www.dailyfinance.com/story/media/media-worldranks-of-women-fantasy-football-playersgrowing/19125945/.

Berry, M. (2010), "Hitting the Jackpot", ESPN, available at: http://www.espn.go.com/espnmag/story? $\mathrm{id}=3288522$

Bloomberg Fantasy Sports, 2010

Boren, C. (2011), "NFL.com ad uses Jamal Charles to remind football players that he's finished this year, but they aren't", 
Washington Post, available at:

http://www.washingtonpost.com/blogs/early-lead/post/nflcom-aduses-jamaal-charles-to-remind-fantasy-football-players-that-hesfinished-this-year-but-theyarent/2011/09/22/gIQAw57DoK_blog.html (accessed 10 November 2011).

Bowman, J, Zoss, J. (1989), Diamonds in the Rough: The Untold History of Baseball, Macmillan Publishing, New York, NY.

Brock, D. (2006), "Leagues of Their Own", Nine: A Journal of Baseball History and Culture, No. 15, pp. 110-113.

Brock, D. (2010), "Twain and Crane: The Old Ball Game”, New York Times, March 14, SP2.

Broughton, D. (2009), "Gatorade, Pepsi gain in avid fan awareness; BK sees increase with fantasy game", Sports Business Journal, November 16-22, pp. 14-15.

Burton, R. (2010a), “The Author of 'Red Badge' Loved the Game More Than His Studies", New York Times, March 14, SP2.

Burton (2010b), "Syracuse and a Civil War Masterpiece", Syracuse University Magazine, Summer, 42-47.

Burton, R. and Finkel, J. (in press, 2013), "Stephen Crane: Baseball and a Red Badge", Nine.

Cooper, M (1995), Baseball Games, Schiffer Publishing, Atglen, Pa.

Christ, P. and Anderson, R. (2011), "The impact of technology on evolving roles of salespeople", Journal of Historical Research in Marketing, Vol. 2, No. 2, 173-193.

Cochran, J. (2005), “Can You Really Learn Basic Probability by Playing a Sports Board Game", The American Statistitian, No. 3, pp. 266-272. 
"Confessions of an NYU Outcast", Mushon.com, available at: http://www.mushon.com/fall08/nmrs/10/20/confessions-ofan-nyu-outcast/ (accessed 28 January 2011).

David, N., Duncan, M. (2006), "Sports Knowledge is Power:

Reinforcing Masculine Privilege through Fantasy League

Participation", Journal of Sport and Social Issues, Vol. 30

No.3, pp. 244-264.

Drayer, J., Dwyer, B., Morse, A., Shapiro, S. and White, J. (2010),

"The effects of fantasy football participation on NFL consumption: A qualitative analysis", Sport Management Review, pp. 129-141.

Dulken, S. (2002), Inventing the $19^{\text {th }}$ Century, NYU Press, New York, NY.

Dunn, K. (2009), "Fantasy Football: Increasingly a Woman's Game, Too", NPR.org, available at:

http://www.npr.org/templates/story/story.php?storyId=11281 1315 (accessed 23 March 2011).

Dwyer, B. (2013) “The Impact of Game Outcomes on Fantasy Football Participation and National Football League Media Consumption", Sport Marketing Quarterly, Vol. 22, No. 1, $33-47$.

Eckardt, D. (2009) "Castrol Scores With Sporting News Fantasy Football Sponsorship", Fantasy Ethos.com, available at: http://fantasyethos.com/2009/11/castrol-scores-withsporting-news-fantasy-football-sponsorship/ (accessed 27 February 2011).

Edelman, M. (2012), "A Short Treatise on Fantasy Sports and the Law: How America Regulates its New National Pastime", Harvard Journal of Sports \& Entertainment Law, Vol. 3, No. 1, Winter, 1-53. 
Eisenberg, L, Waggoner, G. (1984), Rotisserie League Baseball, Bantam Books, New York, NY.

Esser, L. (1994), “The Birth of Fantasy Football”, Fantasy Football Index.

Farquhar, L, Meeds, R. (2007). "Types of Fantasy Sports Users and Their Motivations", Journal of Computer-Mediated Communication, pp. 1208-1228.

Fisher, E. (2010), "Sponsorships, custom-built games boost ad sales", Sports Business Daily, available at: http://www.sportsbusinessdaily.com/Journal/Issues/2010/03/ 20100301/SBJ-In-Depth/Sponsorships-Custom-Built-GamesBoost-Ad-Sales.aspx (accessed 27 March 2011).

Fantasy Sports Trade Association (2011), "Fantasy Sports Sports Participation Sets All-Time Record, Grows Past 32 Million Players", FSTA.org, available at: http://www.fsta.org/blog/fsta-press-release/fantasy-sportsparticipation-sets-all-time-record-grows-past-32-millionplayers (accessed 10 November 2011).

Fantasy Sports Trade Association (2012), "Summer 2012 Fantasy Sports Research Group and IPSOS Study", found at: http://fsta.org/industry_demographics

Harris, B. (2003), “A Wink and a Nod to the Founders of Fantasy Football", available at: http://www.fspnet.com/wink.pdf (accessed 20 September 2011).

Holahan, C. (2006), . "Fantasy Football 2.0", Bloomberg Businessweek, available at: http://www.businessweek.com/technology/content/sep2006/t c20060901_880554.htm (accessed 20 February 2011). 
Hollander, P. (1967), "Dream Team”, found in Strange But True Football Stories, Random House, New York, edited by Z. Hollander, 74-77.

Hounsell, G, Galvez, E. (2010), "Injury”, Television Commercial, Sprint, San Francisco, CA.

Huey, A. (2005), "What if Sports Provides Surfers with Dream Matchups?", Grand Rapids Press, March 8, D2.

IPSOS Public Affairs, (2008), "Study: Fantasy Players Spend Big ", Sports Business Daily, available at:

http://www.sportsbusinessdaily.com/Journal/Issues/2008/11/ 20081117/This-Weeks-News/Study-Fantasy-Players-SpendBig.aspx (accessed 23 March 2011).

Kalb, B. (2012), "The Lost Founder of Baseball Video Games", Grantland, April 9, available at: http://www.grantland.com/story/_id/7793059/johnburgeson-ibm-computer-start-baseball-video-games

Katz, H. (2009), Double Play", Smithsonian, October, 7-8.

Kotler, P. (1991), Marketing management: Analysis, planning, implementation, and control, Prentice-Hall, Englewood Cliffs, N.J.

LaMonica, P. (2006), "Fantasy Football... real money", $C N N$ Money, available at: http://money.cnn.com/2006/08/11/news/companies/fantasyfo otball/ (accessed 10 November 2011).

Lewis, M. (2003), Moneyball, W.W. Norton, New York, NY.

McChesney, R. (1989), "Media Made Sport: A History of Sports Coverage in the United States", from Media, Sports, \& Society, Sage Publications, Newbury Park, edited by Lawrence A. Wenner, 49-69. 
McNeil, W. (2008), All-Stars for the All Time: A Sabermetric Ranking of the Major League Best, MacFarland and Company Inc. Publishers, Jefferson, NC.

Merrihew, L. (2009), "More Castrol Traffic No Fantasy", Compete.com, available at:

http://blog.compete.com/2009/11/03/more-castrol-traffic-nofantasy/ (accessed 27 February 2011).

Miller, S. (2011), Strat-O-Matic Devotees Celebrate Its $50^{\text {th }}$ Anniversary", New York Times, February 14, D5.

"Mustrash Talk", Bloomberg Fantasy Sports, available at: http://www.bloombergsports.com/fanofferings/baseball/must rash/mustrash_talk-your_sister.html (accessed 23 March 2011).

Nudd, T. (2011) "NFL.com Spikes Fantasy-Football Ad With Injured Jamaal Charles", Adweek.com,available at: http://www.adweek.com/adfreak/nflcom-spikes-fantasyfootball-ad-injured-jamaal-charles-135052 (accessed 10 November 2012).

Reilly, E. (2005), Baseball: An Encyclopedia of Popular Culture, University of Nebraska Press, New York, NY.

Rotowire (2011), available at: http://www.rotowire.com/about.htm.

Schauf, M. (2010), "Fantasy Sports History: The GOPPPL.", available at:

http://www.fantasysportsbusiness.com/wordpress/2010/08/05 /fantasy-sports-history-the-gopppl (accessed 4 October 2011).

Schwarz, A. (2004), The Numbers Game: Baseball's Lifelong Fascination with Statistics, Dunne Books, New York, NY. 
Strasser, S. (1989), Satisfaction Guaranteed, Smithsonian Books, Washington.

Tsirulnik, G. (2011), "Toyota, Subway score touchdowns with Yahoo mobile properties", Mobile Marketer, February 3, found at:

http://www.mobilemarketer.com/cms/news/advertising/8971. html.

Walker, S. (2006), Fantasyland: A Sportswriter's Obsessive Bid to Win the World's Most Ruthless Fantasy Baseball League, Penguin Publishing, New York, NY.

"What is Fantasy Football", GirlsFantasyFootball.com, available at: http://www.girlsfantasyfootball.com/what.html (10 March 2011).

Wojitas, G. (1991), "Consumer fantasies fulfill marketer's dream", Direct Marketing, available at: http://www.allbusiness.com/marketing-advertising/251530-1.html.

World Fantasy Games, Fantasy Sport Demographics, available at: http://www.worldfantasygames.com/site_flash/index-3.asp (accessed 23 March 2011).

Wulf, S. (1984), "For The Champion In The Rotisserie League, Joy Is a Yoo-Hoo Shampoo.", Sports Illustrated, 14 May, pp. 814.

Xiong, N. (1997), "Fanasy Sports Gets New Site Online,"The New York Times, available at: http://www.nytimes.com/1997/07/21/business/fantasy-sportsgets-new-site-on-the-web.html (accessed 5 November 2011). 
Fantasy Sports Leagues

(1999), "Yahoo! Sports Hits Home Run With Free Fantasy Baseball", Yahoo! Media Relations, available at: http://docs.yahoo.com/docs/pr/release273.html (accessed 10 November 2011). 


\begin{abstract}
About The Journal of SPORT
The Journal of SPORT brings together in one journal the wide variety of research disciplines in sport and will be published biannually in Summer (July/August) and Winter (January/February). The Journal of SPORT is published by the Center for Sport and Recreation Development at Kent State University. A faculty Advisory Board composed of nationally, as well as internationally recognized faculty participates in the peer mentorship review process. This unique, but distinctive, mentorship process provides opportunities for graduate students, at an array of institutions, to thoroughly analyze and review research in conjunction with a faculty mentor. The number of articles accepted will be limited through a selective review process. After the faculty mentored peer review is completed a final determination is made to accept or reject the article. The Journal of SPORT encourages faculty and/or students to submit their research for review.
\end{abstract}

\title{
Submission Guidelines
}

See www.thejournalofsport.com for Submission Guidelines. 